\title{
Turbulence modelling of multiphase flow in high-pressure trickle-bed reactors
}

\author{
Rodrigo J.G. Lopes, Rosa M. Quinta-Ferreira*

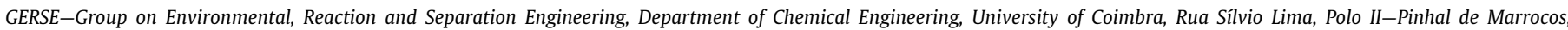 \\ 3030-790 Coimbra, Portugal
}

\section{A R T I C L E I N F O}

\section{Article history:}

Received 17 August 2008

Received in revised form 13 October 2008

Accepted 23 December 2008

Available online 7 January 2009

\section{Keywords:}

Computational fluid dynamics

Trickle-bed reactor

Euler-Euler

Turbulence

Liquid holdup

Pressure drop

\begin{abstract}
A B S T R A C T
Computational fluid dynamics (CFD) has been used as a successful tool for single-phase reactors. However, fixed-bed reactors design depends overly in empirical correlations for the prediction of heat and mass transfer phenomena. Therefore, the aim of this work is to present the application of CFD to the simulation of three-dimensional interstitial flow in a multiphase reactor. A case study comprising a high-pressure trickle-bed reactor (30 bar) was modelled by means of anEuler-Euler CFD model. The numerical simulations were evaluated quantitatively by experimental data from the literature. During grid optimization and validation, the effects of mesh size, time step and convergence criteria were evaluated plotting the hydrodynamic predictions as a function of liquid flow rate. Among the discretization methods for the momentum equation, a monotonic upwind scheme for conservation laws was found to give better computed results for either liquid holdup or two-phase pressure drop since it reduces effectively the numerical dispersion in convective terms of transport equation.

After the parametric optimization of numerical solution parameters, four RANS multiphase turbulence models were investigated in the whole range of simulated gas and liquid flow rates. During RANS turbulence modelling, standard $k-\varepsilon$ dispersed turbulence model gave the better compromise between computer expense and numerical accuracy in comparison with both realizable, renormalization group and Reynolds stress based models. Finally, several computational runs were performed at different temperatures for the evaluation of either axial averaged velocity and turbulent kinetic energy profiles for gas and liquid phases. Flow disequilibrium and strong heterogeneities detected along the packed bed demonstrated liquid distribution issues with slighter impact at high temperatures.
\end{abstract}

(c) 2008 Elsevier Ltd. All rights reserved.

\section{Introduction}

Trickle-bed reactors (TBR) are fixed-bed vertical columns that are mostly operated in concurrent gas-liquid downflow hosting a variety of catalytic reactions mainly in hydrotreating processes (e.g. hydrocracking, hydrodesulfurization, hydrodemetallization) and fine chemicals processing industries and, more recently, in waste gas and wastewater treatment plants (Al-Dahhan et al., 1997).

The design of a TBR depends on the precise knowledge of hydrodynamic parameters as long as the conversion of reactants and selectivity depend not only on reaction kinetics, operating pressure and temperature but also on the hydrodynamics of the reactor. Atmospheric and pressurized TBR experimental studies on hydrodynamic parameters of TBR are reviewed extensively by Saroha and Nigam (1996) and Iliuta et al. (1999) proposing state-of-the-art

* Corresponding author. Tel.: +351 239798723; fax: +351239798703.

E-mail addresses: rodrigo@eq.uc.pt (R.J.G. Lopes), rosaqf@eq.uc.pt (R.M. Quinta-Ferreira). correlations. However, the experimental investigations and its fitting parameters are only confined in a particular range of operation. For this reason the exact mathematical description of two-phase downflow in TBRs based upon the knowledge of complete velocity and holdup field distributions of individual phases is accomplished by means of modern computational fluid dynamics (CFD) codes (Atta et al., 2007; Gunjal et al., 2005a; Jiang et al., 2002).

Initially, mathematical modelling was limited to a twodimensional geometry of a few particles for laminar single-phase flow. As soon as sufficient and increasing computing capabilities became available, three-dimensional simulations were reported in the literature using CFD codes to simulate heat and mass transfers in packed bed (Romkes et al., 2003; Magnico, 2003; Logtenberg et al., 1999). Several computational studies have recently developed mathematical models for simulating single-phase flow in packed beds (Calis et al., 2001; Freund et al., 2003; Tobis, 2000; Zeiser et al., 2002). Numerical simulations of multiphase flow in TBRs were also published ranging from the traditional homogeneous and heterogeneous models without solving the velocity field to the Eulerian and Lagrangian CFD codes. Stanek and Szekely (1974) formulated a 
diffusion model to solve the equations of flow and diffusion, but the effect of gas-liquid interactions is neglected. The relative permeability model was initially proposed by Sáez and Carbonell (1985) where the drag force is calculated by using the concept of relative permeability of each phase. Holub et al. (1992) developed a single slit model for the local flow of liquid and gas around the catalyst particles by assuming flow in rectangular inclined slits of width related to void fraction of the medium. Later, Iliuta et al. (2000) extended the model to allow for a distribution of slits that are totally dry in addition to slits that have liquid flow along the wall. Attou and Ferschneider (1999) developed a fluid-fluid interfacial force model in which the drag force for each phase has contributions from the particle-fluid interaction as well as from the fluid-fluid interaction. Recently, drag exchange coefficients are obtained from the relative permeability concept developed by Sáez and Carbonell (1985) to perform CFD simulations based on a porous media model (Anderson and Sapre, 1991; Souadnia and Latifi, 2001; Atta et al., 2007). Alternatively, in the $k$-fluid model the drag exchange coefficients can be obtained from the fluid-fluid interfacial force model as reported by Jiang et al. (2002) and Gunjal et al. (2005a).

\section{Previous work}

In order to simulate three-dimensional interstitial flow in packed tubes, two CFD approaches have been used to simulate fluid flow in fixed-bed reactors. Firstly, the entire packed bed limited to very low number of particles arranged in either a regular fashion or a random fashion was investigated by Logtenberg et al. (1999) and Calis et al. (2001). Secondly, the so-called unit-cell approach was used to overcome the size of the bed and the number of particles and can be further subdivided as follows. Each particle is assumed to have a hypothetical sphere of influence around it (Dhole et al., 2004) or a unit periodic cell consisting of only a few particles is repeated successively in order to represent the three-dimensional packed bed as reported by Martin et al. (1951) and Sørensen and Stewart (1974) with different packing arrangements of particles.

Depending on the thermophysical properties of fluids, flow rates, and catalyst loading, several types of flow patterns were observed experimentally by several authors. Mickley et al. (1965) found that eddy shedding did not occur in the packing voids and that high local heat transfer coefficients in spherical packings must be due to turbulence intensity in the voids quantified as high as $50 \%$. In regular packings, Van der Merwe and Gauvin (1971) observed no eddy shedding over the range $2500<\operatorname{Re}<27,000$ except on the first bank of spheres and turbulence intensity values were about $25 \%$. The transition from steady to unsteady flow in a dumped bed of spheres in the range $110<R e<150$ was found by Jolls and Hanratty (1966) who observed a vigorous eddying motion that they took to indicate turbulence at $R e=300$. Wegner et al. (1971) observed completely steady flow with nine regions of reverse flow on the surface of the sphere for $R e=82$ in regular beds of spheres monitoring similar flow elements but with different sizes in an unsteady flow at $R e=200$. Dybbs and Edwards (1984) used laser anemometry and flow visualization to study flow regimes of liquids in hexagonal packings of spheres and rods and concluded that there are four flow regimes for different ranges of Reynolds number, based on interstitial or pore velocity $R e_{i}=R e / \varepsilon$ : for $R e_{i}<1$, the creeping flow is dominated by viscous forces and pressure drop is linearly proportional to interstitial velocity; for $1 \leqslant R e_{i} \leqslant 150$, the steady laminar inertial flow in which pressure drop depends nonlinearly on interstitial velocity; for $150 \leqslant R e_{i} \leqslant 300$, the laminar inertial flow is unsteady; and for $R_{i}>300$, the flow is highly unsteady, chaotic and qualitatively resembling turbulent flow. Latifi et al. (1989) used microelectrodes as electrochemical sensors to get more precise regime transitions and later Rode et al. (1994) included the transfer function of the electrochemical probe and gave the tran- sition to time-dependent chaotic flow as $110<R e<150$. Seguin et al. (1998a) found extremely non-homogeneous at different spatial locations in a packed tube occurring at $R e=113$ inside the bed and at $R e=135$ at the wall. Seguin et al., 1998b found that the transition to the turbulent regime is gradual and not at the same Re at all locations after performing the stabilization of the fluctuation rate which corresponds to local turbulence at $90 \%$ of the electrodes for $R e>600$.

Several computational studies have been also performed on the turbulence modelling of fluid flow in packed-beds. Hill et al. $(2001 a, b)$ investigated the effects of inertia on flows in both ordered and random arrays of spheres for small and moderate Re by means of lattice-Boltzmann simulations. Stevenson (2003) indicated that the transition from laminar flow to turbulence may occur at much lower $R e$ in a packed tube than an empty one, due to the reduced viscous damping of radial velocity components caused by flow instabilities. Logtenberg et al. (1999) used a finite element code to simulate two layers of four spheres in laminar and turbulent flow based on $k-\varepsilon$ turbulence model $(9<R e<1450)$. With a mesh composed of 30,747 tetrahedral cells, they found reasonable agreement for Nusselt number and effective thermal conductivity compared with experimental values. Romkes et al. (2003) used CFD simulations to predict mass and heat transfer in a packed bed of 32 spheres, both in laminar and turbulent flow. The transfer rates were obtained with an average error of $15 \%$ compared with experimental data for Reynolds number either based on interstitial velocity or hydraulic diameter from $10^{-1}$ to $10^{5}$. Magnico (2003) presented a numerical sensitivity study of meshing and solving parameters in laminar fluid flow and mass transfer in a packed bed of several hundred of spheres. Guardo et al. (2005) compared the numerical prediction obtained with five turbulence models (Spalart-Almaras, standard $k-\varepsilon$, RNG $k-\varepsilon$, realizable $k-\varepsilon$, standard $k-w$ ) for a packed bed of 44 spheres. The best agreement with commonly used correlations was obtained with the Spalart-Almaras model which is less sensitive to the near-wall treatment. Gunjal et al. (2005b) used a laminar model up to $R e_{i}=204$ and turbulent models for $R e_{i}=1000-2000$. Merrikh and Lage (2005) used the CFD approach in the case of natural convection within up to 64 solid particles. They studied fluid flow and heat transfer in a differentially heated square enclosure with disconnected solids blocks.

\section{Present work}

From the above survey, the detail of the fluid flow mechanical studies on particle arrays is not in accordance on which range for Reynolds number split the laminar flow from the turbulent flow. In the present work, we perform an evaluation of either laminar or different Reynolds averaged Navier-Stokes (RANS) turbulence models (standard, realizable and RNG $k-\varepsilon$, Reynolds stress model, RSM) for multiphase flow in TBR. A multifluid Eulerian model is presented with interphase coupling parameters in the momentum balance equation from the work developed by Attou and Ferschneider (1999). A TBR with regular packing is considered as the base geometry for the simulation of the three-dimensional interstitial flow to describe the fluid phase scale interactions at the catalyst level. As long as the details of the flow environment around the catalyst particles are essential, different mesh densities in the optimization of numerical solution parameters (time step, convergence criteria and differencing scheme of governing equations) have to be performed under unsteady laminar and turbulent flow simulations in order to provide a more fundamental understanding of trickle-bed hydrodynamics. To the best of our knowledge, this investigation on multiphase flow turbulence is sought here in order to incorporate more realistic fluid flow and evaluate in detail three-dimensional velocity and turbulent kinetic energy profiles as well. 


\section{CFD modelling}

\subsection{Euler-Euler momentum equation}

Multiphase flow in the TBR was modelled using a CFD multiphasic approach incorporated in the Fluent 6.1 software that is the Euler-Euler multiphase model. In the Eulerian two-fluid approach, the different phases are treated mathematically as interpenetrating continua. The derivation of the conservation equations for mass, momentum and energy for each of the individual phases is done by ensemble averaging the local instantaneous balances for each of the phases. The current model formulation specifies that the probability of occurrence of any one phase in multiple realizations of the flow is given by the instantaneous volume fraction of that phase at that point where the total sum of all volume fractions at a point is identically unity. Fluids, gas and liquid, are treated as incompressible, and a single pressure field is shared by all phases. Conservation equations in this section are shown in terms of rectangular Cartesian coordinates. The continuity (1) and momentum equations (2) are solved for each phase and the momentum transfer between the phases is modelled through a drag term, which is a function of the local velocity between the phases.

$\frac{\partial U_{x}}{\partial x}+\frac{\partial U_{y}}{\partial y}+\frac{\partial U_{z}}{\partial z}=0$

$\frac{\mathrm{D}}{\mathrm{D} t}\left(\alpha_{i} \rho_{i} \vec{U}_{i}\right)=-\alpha_{i} \nabla p+\nabla \cdot \hat{\tau}_{i}+\alpha_{i} \rho_{i} \vec{g}+\sum_{p=1}^{n} \vec{F}_{i j}\left(\vec{U}_{i j}-\vec{U}_{j i}\right)$

\subsection{Drag force formulation}

Interphase coupling terms, $\vec{F}_{i j}$, in the right side of Eq. (2) were formulated based on similar equations to those that are typically used to express the pressure drop for packed beds by means of the Ergun equation. Consequently, the model of Attou and Ferschneider (1999) was employed in the CFD model, which includes gas-liquid interaction forces and it was developed for the regime in which liquid flows in the form of film. The interphase coupling terms are expressed in terms of interstitial velocities and phase volume fractions for gas-liquid, gas-solid and liquid-solid momentum exchange forms

$$
\begin{aligned}
F_{G L}= & \varepsilon_{G}\left(\frac{E_{1} \mu_{G}\left(1-\varepsilon_{G}\right)^{2}}{\varepsilon_{G}^{2} d_{p}^{2}}\left[\frac{\varepsilon_{S}}{1-\varepsilon_{G}}\right]^{2 / 3}+\frac{E_{2} \rho_{G}\left(u_{G}-u_{L}\right)\left(1-\varepsilon_{G}\right)}{\varepsilon_{G} d_{p}}\right. \\
& \left.\times\left[\frac{\varepsilon_{S}}{1-\varepsilon_{G}}\right]^{1 / 3}\right) \\
F_{G S}= & \varepsilon_{G}\left(\frac{E_{1} \mu_{G}\left(1-\varepsilon_{G}\right)^{2}}{\varepsilon_{G}^{2} d_{p}^{2}}\left[\frac{\varepsilon_{S}}{1-\varepsilon_{G}}\right]^{2 / 3}+\frac{E_{2} \rho_{G} u_{G}\left(1-\varepsilon_{G}\right)}{\varepsilon_{G} d_{p}}\left[\frac{\varepsilon_{S}}{1-\varepsilon_{G}}\right]^{1 / 3}\right) \\
F_{L S}= & \varepsilon_{L}\left(\frac{E_{1} \mu_{L} \varepsilon_{S}^{2}}{\varepsilon_{L}^{2} d_{p}^{2}}+\frac{E_{2} \rho_{L} u_{G} \varepsilon_{S}}{\varepsilon_{L} d_{p}}\right)
\end{aligned}
$$

\subsection{RANS turbulence modelling}

Aiming to describe the effects of turbulent fluctuations of velocities and scalar quantities for the multiphase flow in the present case study, three methods were investigated for modelling turbulence in the trickle-bed within the context of the $k-\varepsilon$ models. Standard, RNG, and realizable models have similar forms being the major difference between them the calculation of turbulent viscosity and turbulent Prandtl numbers. For this reason only the additional options for the
Table 1

$k-\varepsilon$ mixture turbulence model.

\begin{tabular}{l} 
Transport equations \\
$\frac{\partial}{\partial t}\left(\rho_{m} k\right)+\nabla\left(\rho_{m} \vec{u}_{m} k\right)=\nabla\left(\frac{\mu_{t, m}}{\sigma_{k}} \nabla k\right)+G_{k, m}-\rho_{m} \varepsilon$ \\
$\frac{\partial}{\partial t}\left(\rho_{m} \varepsilon\right)+\nabla\left(\rho_{m} \vec{u}_{m} \varepsilon\right)=\nabla\left(\frac{\mu_{t, m}}{\sigma_{\varepsilon}} \nabla \varepsilon\right)+\frac{\varepsilon_{m}}{k_{m}} \times\left(C_{1 \varepsilon} G_{k, m}-C_{2 \varepsilon} \rho_{m} \varepsilon\right)$ \\
$\rho_{m}=\sum_{i=1}^{N} \alpha_{i} \rho_{i}, \quad \vec{u}_{m}=\frac{\sum_{i=1}^{N} \alpha_{i} \rho_{i} \vec{u}_{i}}{\sum_{i=1}^{N} \alpha_{i} \rho_{i}}, \quad \mu_{t, m}=\rho_{m} C_{\mu} \frac{k^{2}}{\varepsilon}$ \\
$G_{k, m}=\mu_{t, m}\left(\nabla \vec{u}_{m}+\left(\nabla \vec{u}_{m}\right)^{T}\right): \nabla \vec{u}_{m}$ \\
\hline
\end{tabular}

Table 2

$k-\varepsilon$ dispersed turbulence model.

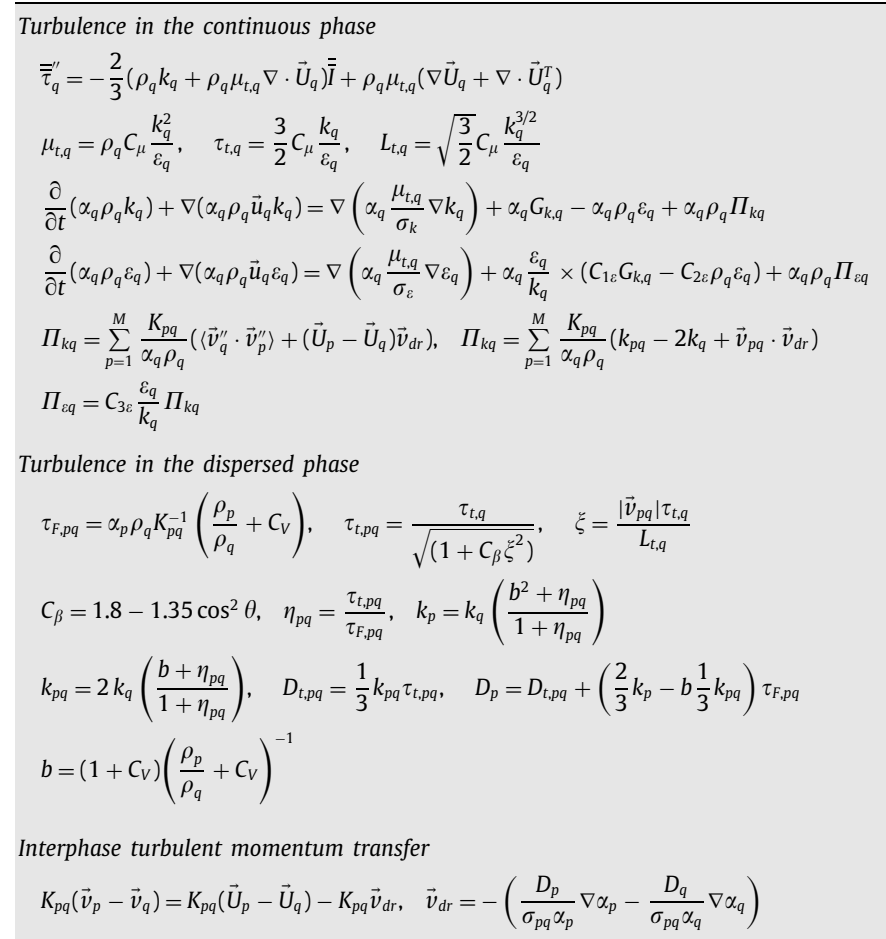

standard $k-\varepsilon$ turbulence model are described in Tables $1-3$ that are mixture turbulence model, dispersed turbulence model (which is the default model used through the Eulerian simulations) and finally a turbulence model for each phase, respectively. In what concerns the RSM (Table 4) only two options were examined that are the mixture turbulence model and the dispersed turbulence model.

\section{Numerical simulation}

\subsection{Trickle-bed geometry, fluid properties, operating and boundary conditions}

The present case-study encompass a TBR that was designed using regular shape catalyst particles for multifluid Eulerian simulations (Lopes and Quinta-Ferreira, 2007). Gas-liquid flows through a catalytic bed comprised of monosized, spherical, solid particles arranged in a cylindrical container of a pilot TBR unit $(50 \mathrm{~mm}$ internal diameter $\times 1.0 \mathrm{~m}$ length). The computational mesh of the catalytic bed was shortened in length given the high memory requirements so that the reactor was filled with 13 layers where approximately 200 non-overlapping spherical particles of $2 \mathrm{~mm}$ diameter were necessary for each axial layer as shown in Fig. 1. In order to prevent numerical difficulties associated with the mesh generation also reported in the literature (Logtenberg et al., 1999), the 
Table 3

$k-\varepsilon$ turbulence model for each phase.

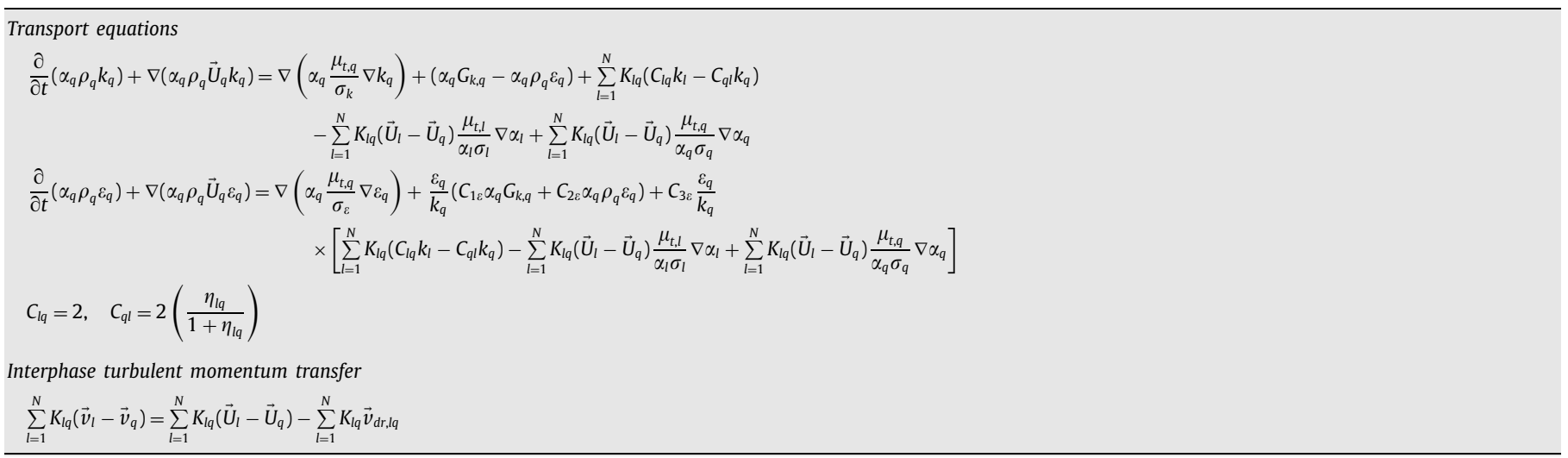

Table 4

RSM turbulence models.

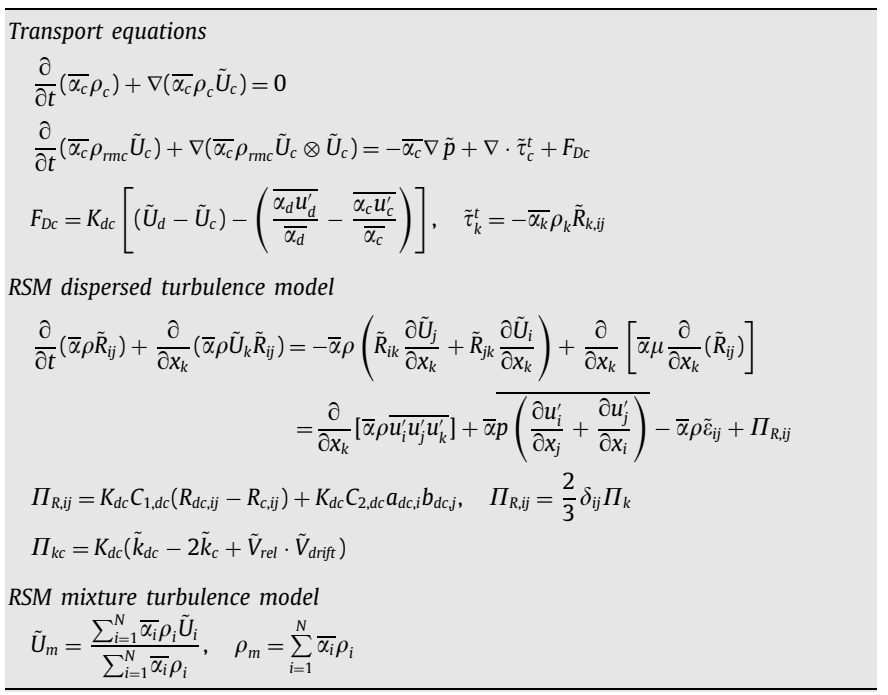

catalyst particles do not touch each other and the distance gap was fixed by $2-3 \%$ of the sphere diameter. The grid of catalytic bed was created using the integrated solid modelling and meshing commercial program Gambit. Geometrical errors arising from the mesh style and quality were evaluated according to different mesh densities and discretization parameters. Consecutively, the number of cells necessary to produce grid independent results for the hydrodynamic parameters was increased from $2 \times 10^{5}$ to $10^{6}$, with other numerical solution parameters including operating conditions given by Table 5 . Gas and liquid thermophysical properties used in the simulation are summarized in Table 6. High-pressure operation was simulated at 30 bar total operating pressure with inflow gas $\left(\mathrm{G}=0.1-0.7 \mathrm{~kg} / \mathrm{m}^{2} \mathrm{~s}\right)$ and liquid $\left(\mathrm{L}=1-15 \mathrm{~kg} / \mathrm{m}^{2} \mathrm{~s}\right.$ ) being distributed uniformly with given superficial velocity replicating a uniform distributor at the top of TBR.

The boundary conditions were specified based on Fluent documentation. Inlet turbulent kinetic energy $(k)$ was estimated from turbulence intensity as expressed in Eq. (6).

$k=\frac{3}{2}(u I)^{2}$

where $I$ is the turbulence intensity being given by Eq. (7).

$I=0.16\left(R e_{d_{H}}\right)^{-1 / 8}$

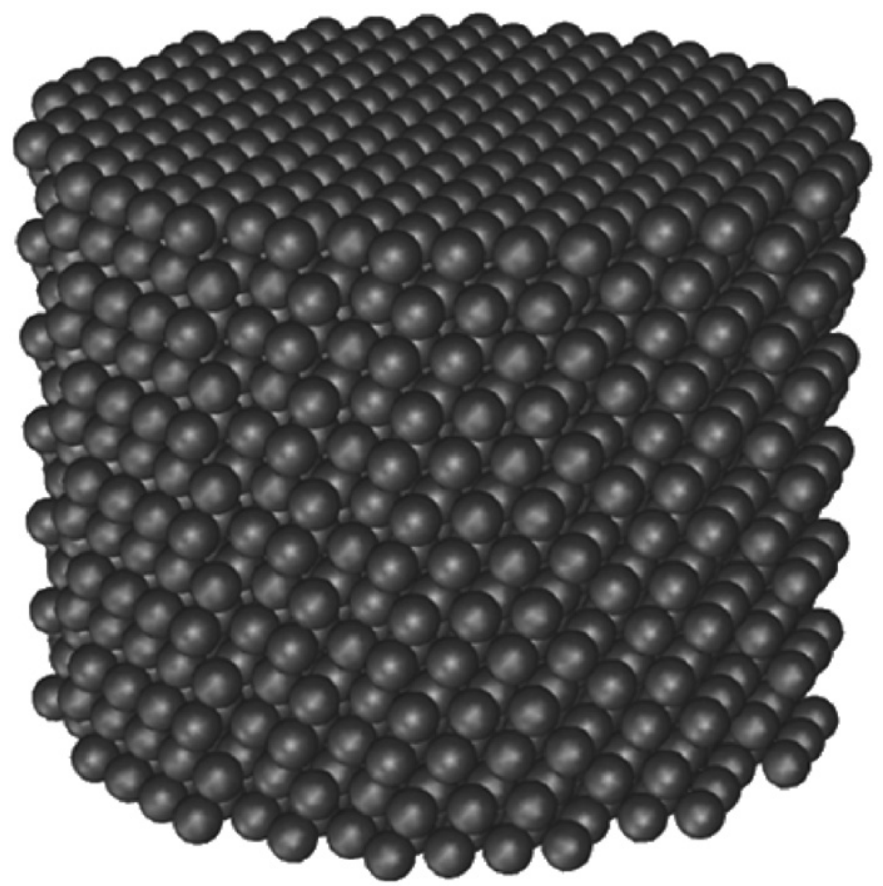

Fig. 1. Schematic of the catalytic packing geometry for the trickle-bed reactor.

Inlet turbulent dissipation rate $(\varepsilon)$ was estimated from the turbulent viscosity ratio as expressed by Eq. (8).

$\varepsilon=\rho C_{\mu} \frac{k^{2}}{\mu}\left(\frac{\mu_{t}}{\mu}\right)^{-1}$

where $C_{\mu}$ is an empirical constant specified in the turbulence model (0.09). At 30 bar, two temperatures 25 and $200^{\circ} \mathrm{C}$, the inlet turbulent kinetic energy and inlet turbulent dissipation rate for the gas and liquid phases are given in Table 7. Computations are time dependent and were carried out until steady state conditions were reached. Standard wall functions available in the commercial CFD solver were employed during the simulations of turbulent multiphase flow. The calculations have been carried out on a Linux cluster based on AMD64 Dual-Core $2.2 \mathrm{GHz}$ processor workstation.

\subsection{Solution method: pressure-correction and volume fraction equations}

For Eulerian multiphase calculations, it was employed the phase coupled SIMPLE (PC-SIMPLE: Vasquez and Ivanov, 2000) algorithm 
for the pressure-velocity coupling which is an extension of the SIMPLE algorithm (Patankar, 1980) to multiphase flows. The velocities are solved coupled by phases, but in a segregated fashion. The block algebraic multigrid scheme used by the density-based solver described is used to solve a vector equation formed by the velocity components of all phases simultaneously. Then, a pressure correction equation is built based on total volume continuity rather than mass continuity. Pressure and velocities are then corrected so as

Table 5

Numerical solution parameters used in the CFD simulation.

\begin{tabular}{ll}
\hline Grid & $1000 \mathrm{~mm}$ (axial) $\times 50 \mathrm{~mm}$ (radial) \\
Cell size & $0.01-0.20 \mathrm{~mm}$ (tetrahedral cells) \\
Particle diameter & $2 \mathrm{~mm}(\mathrm{spheres})$ \\
Time step & $10^{-5}-10^{-2} \mathrm{~s}$ \\
Convergence criteria & $10^{-5}-10^{-2}$ \\
Discretization & \\
$\quad$ Momentum & FOU, SOU, power-law, QUICK, MUSCL \\
$\quad$ Volume fraction & FOU, QUICK \\
$\quad$ Turbulent kinetic energy & FOU, SOU, power-law, QUICK, MUSCL \\
Turbulent dissipation rate & FOU, SOU, power-law, QUICK, MUSCL \\
Iterations & $\approx 10-50,000$ \\
Under-relaxation parameters & Pressure: 0.3 \\
& Density: 1 \\
& Body forces: 1 \\
& Momentum: 0.7 \\
& Volume fraction: 1 \\
& Turbulent kinetic energy: 0.8 \\
& Turbulent dissipation rate: 0.8 \\
& Turbulent viscosity: 1 \\
Drag formulation & Attou and Ferschneider (1999) \\
Turbulence model & SKE, RKE, RNG, RSM \\
\hline
\end{tabular}

Table 6

Relevant thermophysical properties of gas and liquid phases.

\begin{tabular}{|c|c|c|c|}
\hline \multirow[t]{2}{*}{ Properties } & \multicolumn{2}{|c|}{ Value $(P=30$ bar $)$} & \multirow[t]{2}{*}{ Units } \\
\hline & $T_{1}=25^{\circ} \mathrm{C}$ & $T_{1}=200^{\circ} \mathrm{C}$ & \\
\hline \multicolumn{4}{|l|}{ Liquid phase } \\
\hline Viscosity & $8.925 \times 10^{-4}$ & $1.340 \times 10^{-4}$ & Pas \\
\hline Density & 998.4 & 866.9 & $\mathrm{~kg} / \mathrm{m}^{3}$ \\
\hline Surface tension & $7.284 \times 10^{-2}$ & $3.770 \times 10^{-2}$ & $\mathrm{Nm}$ \\
\hline Thermal conductivity & $6.063 \times 10^{-1}$ & $6.657 \times 10^{-1}$ & $\mathrm{~W} / \mathrm{mK}$ \\
\hline \multicolumn{4}{|l|}{ Gas phase } \\
\hline Viscosity & $1.845 \times 10^{-5}$ & $2.584 \times 10^{-5}$ & Pas \\
\hline Density & 35.67 & 21.97 & $\mathrm{~kg} / \mathrm{m}^{3}$ \\
\hline Thermal conductivity & $2.708 \times 10^{-2}$ & $3.839 \times 10^{-2}$ & $\mathrm{~W} / \mathrm{mK}$ \\
\hline
\end{tabular}

to satisfy the continuity constraint. For incompressible multiphase flow, the pressure-correction equation takes the following form:

$$
\sum_{k=1}^{n} \frac{1}{\rho_{r k}}\left\{\frac{\partial}{\partial t} \alpha_{k} \rho_{k}+\nabla \cdot \alpha_{k} \rho_{k} \vec{v}_{k}^{\prime}+\nabla \cdot \alpha_{k} \rho_{k} \vec{v}_{k}^{*}-\left(\sum_{l=1}^{n}\left(\dot{m}_{l k}-\dot{m}_{k l}\right)\right)\right\}=0
$$

where $\rho_{r k}$ is the phase reference density for the $k$ th phase (defined as the total volume average density of phase $k$ ), $\vec{v}_{k}^{\prime}$ is the velocity correction for the $k$ th phase, and $\vec{v}_{k}^{*}$ is the value of $\vec{v}_{k}$ at the current iteration. The velocity corrections are themselves expressed as functions of the pressure corrections.

The volume fractions are obtained from the phase continuity equations. In discretized form, the $k$ th volume fraction is given as

$a_{p, k} \alpha_{k}=\sum_{n b}\left(a_{n b, k} \alpha_{n b, k}\right)+b_{k}=R_{k}$

These equations satisfy the condition that all the volume fractions sum to one as expressed below

$\sum_{k=1}^{n} \alpha_{k}=1$

\section{Results and discussion}

\subsection{Parametric optimization of mesh size, time step and convergence criteria}

The liquid holdup and pressure drop predicted by the CFD simulations are quantitatively compared with the literature experimental results (Nemec and Levec, 2005). We begin with a base case examining the influence of model solution parameters including different mesh apertures, time steps as well as convergence criteria. Concerning the mesh sensitivity analysis, several computational runs were performed changing the mesh density in the catalyst particle surface in order to properly capture the boundary layer.

In Fig. 2 it is plotted four simulation sets of liquid holdup as a function of liquid flow rate at $P=30$ bar and $G=0.1 \mathrm{~kg} / \mathrm{m}^{2} \mathrm{~s}$ with the coarsest mesh which corresponds to about $2 \times 10^{5}$ tetrahedral cells and the finest mesh with one million tetrahedral cells. The spatial resolution is about $d_{p} / 20$ which gives an average cell size of $0.05-0.2 \mathrm{~mm}$ for the finer meshes depending on the packing geometry of the catalytic bed. As it can be seen from Fig. 2, low mesh density $\left(2 \times 10^{5}\right.$ of tetrahedral cells) at particle surface led to

Table 7

Inlet boundary conditions for the gas and liquid phases: turbulent kinetic energy $\left(k_{i}\right)$ and turbulent dissipation rate $\left(\varepsilon_{i}\right)$ at $P=30$ bar.

\begin{tabular}{|c|c|c|c|c|c|c|}
\hline$G\left(\mathrm{~kg} / \mathrm{m}^{2} \mathrm{~s}\right)$ & $L\left(\mathrm{~kg} / \mathrm{m}^{2} \mathrm{~s}\right)$ & $T\left({ }^{\circ} \mathrm{C}\right)$ & $k_{G}\left(\mathrm{~mm}^{2} / \mathrm{s}^{2}\right)$ & $k_{L}\left(\mathrm{~mm}^{2} / \mathrm{s}^{2}\right)$ & $\varepsilon_{G}\left(\mathrm{~mm}^{2} / \mathrm{s}^{3}\right)$ & $\varepsilon_{L}\left(\mathrm{~mm}^{2} / \mathrm{s}^{3}\right)$ \\
\hline 0.1 & 1 & 25 & 0.2059 & $3.952 \times 10^{-2}$ & $3.690 \times 10^{-3}$ & $7.637 \times 10^{-5}$ \\
\hline 0.4 & 1 & 25 & 2.330 & $3.952 \times 10^{-2}$ & 0.4723 & $7.637 \times 10^{-5}$ \\
\hline 0.7 & 1 & 25 & 6.204 & $3.952 \times 10^{-2}$ & 3.349 & $7.637 \times 10^{-5}$ \\
\hline 0.1 & 8 & 25 & 0.2059 & 1.504 & $3.690 \times 10^{-3}$ & 0.1106 \\
\hline 0.4 & 8 & 25 & 2.330 & 1.504 & 0.4723 & 0.1106 \\
\hline 0.7 & 8 & 25 & 6.204 & 1.504 & 3.349 & 0.1106 \\
\hline 0.1 & 15 & 25 & 0.2059 & 4.518 & $3.690 \times 10^{-3}$ & 0.9982 \\
\hline 0.4 & 15 & 25 & 2.330 & 4.518 & 0.4723 & 0.9982 \\
\hline 0.7 & 15 & 25 & 6.204 & 4.518 & 3.349 & 0.9982 \\
\hline 0.1 & 1 & 200 & 0.5907 & $3.219 \times 10^{-2}$ & $1.335 \times 10^{-2}$ & $3.015 \times 10^{-4}$ \\
\hline 0.4 & 1 & 200 & 6.683 & $3.219 \times 10^{-2}$ & 1.709 & $3.015 \times 10^{-4}$ \\
\hline 0.7 & 1 & 200 & 17.79 & $3.219 \times 10^{-2}$ & 12.119 & $3.015 \times 10^{-4}$ \\
\hline 0.1 & 8 & 200 & 0.5907 & 1.225 & $1.335 \times 10^{-2}$ & 0.4367 \\
\hline 0.4 & 8 & 200 & 6.683 & 1.225 & 1.709 & 0.4367 \\
\hline 0.7 & 8 & 200 & 17.79 & 1.225 & 12.119 & 0.4367 \\
\hline 0.1 & 15 & 200 & 0.5907 & 3.680 & $1.335 \times 10^{-2}$ & 3.941 \\
\hline 0.4 & 15 & 200 & 6.683 & 3.680 & 1.709 & 3.941 \\
\hline 0.7 & 15 & 200 & 17.79 & 3.680 & 12.11 & 3.941 \\
\hline
\end{tabular}




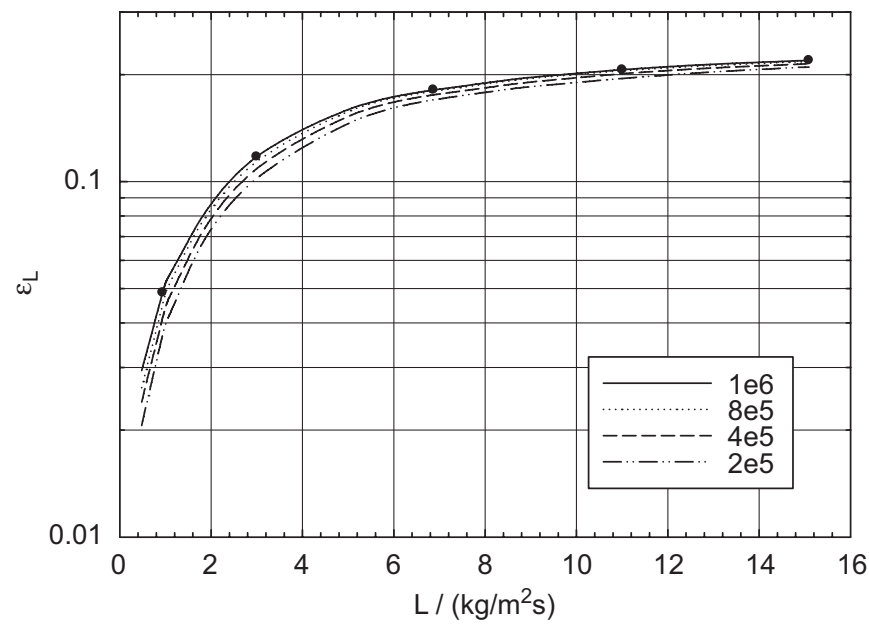

Fig. 2. Comparison of liquid holdup predictions as a function of liquid flow rate for different mesh resolutions $\left(G=0.1 \mathrm{~kg} / \mathrm{m}^{2} \mathrm{~s}, P=30 \mathrm{bar}, d_{p}=2 \mathrm{~mm}\right.$ and experimental data represented by dots from Nemec and Levec, 2005).

erroneous solutions due to an incorrect definition of boundary layer. As long as the mesh density increases, the theoretical predictions of liquid holdup improves considerably. The experimental data used for the parametric optimization were available from the work developed by Nemec and Levec (2005) in where it was described in detail the experimental setup. In that work, liquid holdup was measured by a gravimetric method that consists in weighing the column in two different ways to have good reproducibility. After the bed was extensively prewetted, the reactor with dimensions similar to the ones described previously was operated first in a high interaction regime and then reduced to the desired level at which the pressure drop and liquid holdup were measured. According to Fig. 2 in where it was plotted the experimental data represented by dots from the work of Nemec and Levec (2005), the liquid holdup numerical simulations performed at $L=1 \mathrm{~kg} / \mathrm{m}^{2} \mathrm{~s}$ with the coarser meshes $\left(2 \times 10^{5}, 4 \times 10^{5}\right)$ gave a relative error of 23.8 and $14.9 \%$, while the finer meshes $\left(8 \times 10^{5}, 10^{6}\right)$ gave 7.1 and $1.5 \%$ of relative error, respectively. At $L=15 \mathrm{~kg} / \mathrm{m}^{2} \mathrm{~s}$, the relative errors for the computed liquid holdup results were $4.1,2.1,1.7$ and $1.0 \%$. As a result, $10^{6}$ tetrahedral cells correspond to the optimum number which gave mesh-independent results with respect to liquid holdup. Frictional pressure drop predictions as a function of liquid flow rate at highpressure operation are plotted in Fig. 3 as well as the experimental data representedby dots from the work developed by Nemec and Levec (2005). At $P=30$ bar and $L=1 \mathrm{~kg} / \mathrm{m}^{2} \mathrm{~s}$, the relative errors obtained for the two-phase pressure drop were 32.7, 16.3, 5.2 and $1.6 \%$ from the coarse to the fine meshes, respectively. If the operation is simulated at the lowest liquid flow rate $\left(L=15 \mathrm{~kg} / \mathrm{m}^{2} \mathrm{~s}\right)$, the relative errors became lesser $41.3,6.6,1.4$ and $1.0 \%$ for $2 \times 10^{5}, 4 \times 10^{5}$, $8 \times 10^{5}$ and $10^{6}$ tetrahedral cells, respectively. Therefore, both hydrodynamic parameters are underpredicted if one uses a coarse mesh. The same value for the number of tetrahedral cells were achieved for mesh-independent results with respect to both liquid holdup and pressure drop with the finest mesh so that it was used as the base case setting for subsequent parametric investigation of other model solution parameters.

Using as the base case the finest tetrahedral mesh with about one million cells, several computational runs were carried out with different time steps. Taking into account that a nominal time step in the range $10^{-2}-10^{-3} \mathrm{~s}$ has often been used in the Eulerian simulations for gas-liquid flows (Lopes and Quinta-Ferreira, 2008; Gunjal et al., 2005b; Jiang et al., 2002), this model parameter was selected in the parametric study with values of $10^{-5}, 10^{-4}, 10^{-3}$ and $10^{-2} \mathrm{~s}$.

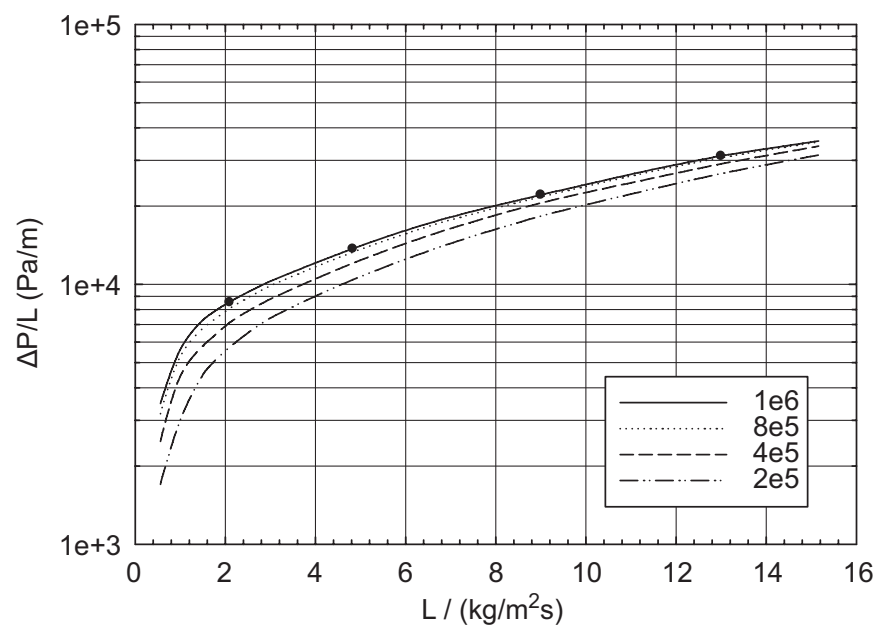

Fig. 3. Comparison of two-phase pressure drop predictions as a function of liquid flow rate for different mesh resolutions $\left(G=0.5 \mathrm{~kg} / \mathrm{m}^{2} \mathrm{~s}, P=30 \mathrm{bar}, d_{p}=2 \mathrm{~mm}\right.$ and experimental data represented by dots from Nemec and Levec, 2005).

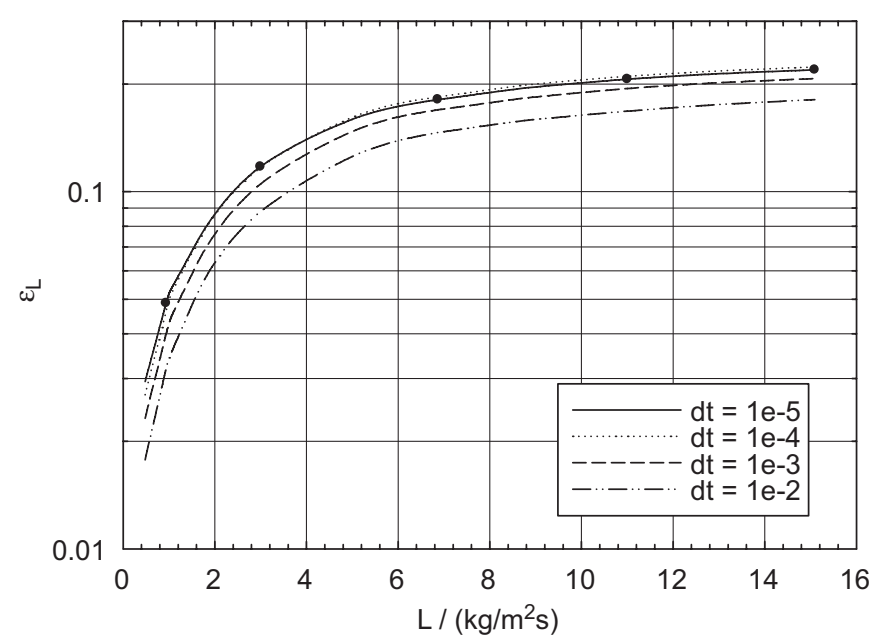

Fig. 4. Effect of time step on liquid holdup predictions as a function of liquid flow rate with the finest mesh $\left(10^{6}\right.$ of tetrahedral cells, $G=0.1 \mathrm{~kg} / \mathrm{m}^{2} \mathrm{~s}, P=30 \mathrm{bar}$, $d_{p}=2 \mathrm{~mm}$ and experimental data represented by dots from Nemec and Levec, 2005).

In Fig. 4 it is plotted the computed liquid holdup as a function of liquid flow rate at $P=30$ bar and $G=0.1 \mathrm{~kg} / \mathrm{m}^{2} \mathrm{~s}$ with these time step values. As one can conclude, the decrease of time step from $10^{-2}$ to $10^{-3}$ and further to $10^{-4} \mathrm{~s}$ gave better agreement between the Eulerian model predictions and experimental data. However, a subsequent decrease to $10^{-5} \mathrm{~s}$ did not show any significant gain in numerical accuracy indicating that it reached an asymptotic solution. In fact, the numerical predictions of liquid holdup at $P=30$ bar and $G=0.1 \mathrm{~kg} / \mathrm{m}^{2} \mathrm{~s}$ with the highest liquid flow rate exhibited a relative error of $17.4,5.4,1.9$ and $1.0 \%$ for time steps of $10^{-2}, 10^{-3}, 10^{-4}$ and $10^{-5} \mathrm{~s}$, respectively. In what concerns the predicted pressure field, in Fig. 5 it was plotted two-phase pressure drop as a function of liquid flow rate. The relative errors obtained at $P=30$ bar and $L=15 \mathrm{~kg} / \mathrm{m}^{2} \mathrm{~s}$ of $20.0,7.9,2.3$ and $1.0 \%$ demonstrated that a time step of $10^{-4} \mathrm{~s}$ gave a good compromise between computational power and the respective numerical accuracy achieved with both liquid holdup and pressure drop.

Aiming to examine the influence of different convergence criteria on the hydrodynamics predictions, different scaled residual 


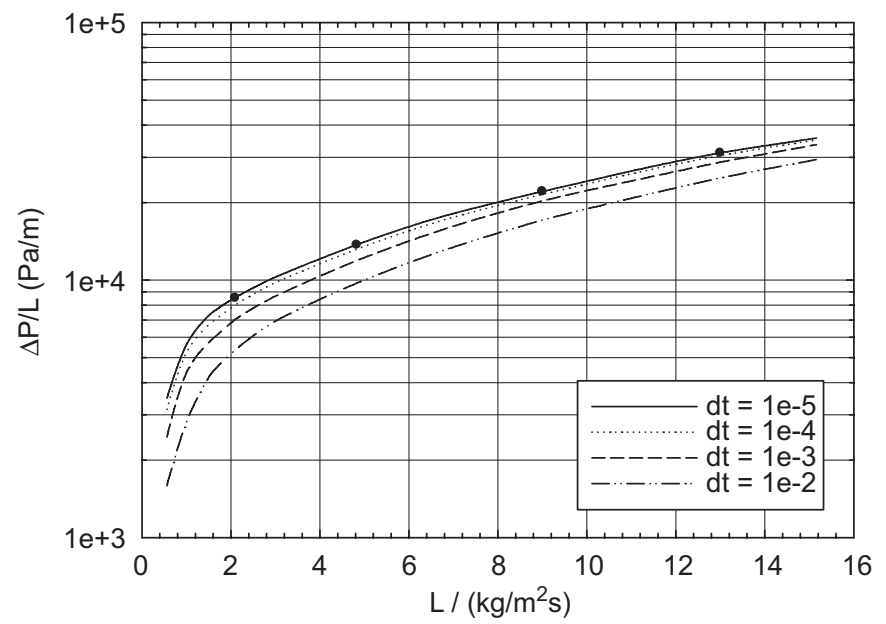

Fig. 5. Effect of time step on two-phase pressure drop predictions as a function of liquid flow rate with the finest mesh $\left(10^{6}\right.$ of tetrahedral cells, $G=0.5 \mathrm{~kg} / \mathrm{m}^{2} \mathrm{~s}$, $P=30$ bar, $d_{p}=2 \mathrm{~mm}$ and experimental data represented by dots from Nemec and Levec, 2005).

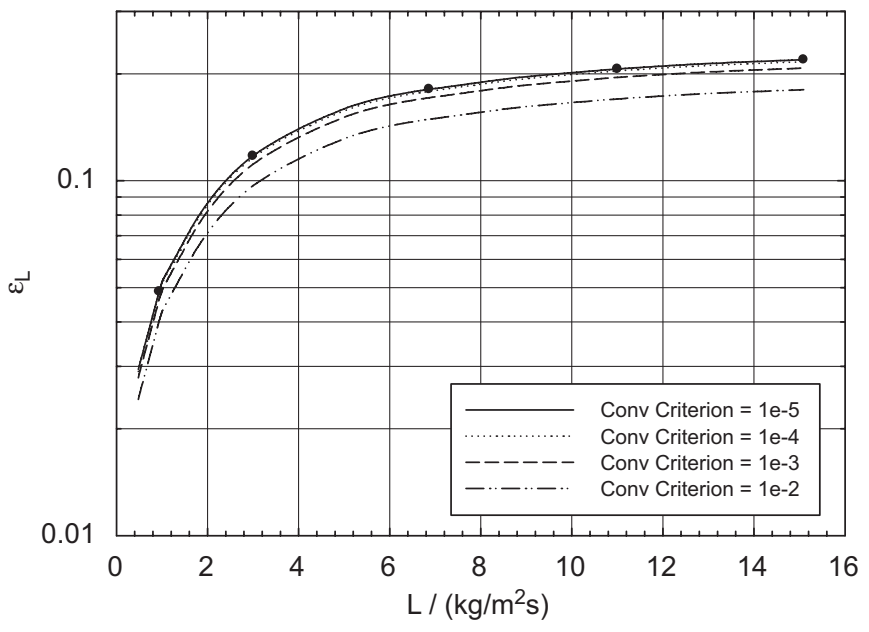

Fig. 6. Effect of convergence criteria on liquid holdup predictions as a function of liquid flow rate (time step $=10^{-5} \mathrm{~s}, 10^{6}$ of tetrahedral cells, $G=0.1 \mathrm{~kg} / \mathrm{m}^{2} \mathrm{~s}, P=30 \mathrm{bar}$, $d_{p}=2 \mathrm{~mm}$ and experimental data represented by dots from Nemec and Levec, 2005).

components of mass, $x, y, z$-velocity and turbulent kinetic energy and turbulent dissipation rates were investigated in the range $10^{-5}$, $10^{-4}, 10^{-3}$ and $10^{-2}$. Liquid holdup predictions as a function of liquid flow rate with different convergence criteria at $P=30$ bar and $G=0.1 \mathrm{~kg} / \mathrm{m}^{2} \mathrm{~s}$ are plotted in Fig. 6 . According to this plot, it was found that changing the convergence criteria method produced almost the same effect as observed with different time steps. In fact, the relative errors between the computed results and experimental data were 17.6, 5.3, 1.2 and 1.0 at the highest liquid flow rate $\left(L=15 \mathrm{~kg} / \mathrm{m}^{2} \mathrm{~s}\right)$ with scaled residual components of $10^{-2}, 10^{-3}, 10^{-4}$ and $10^{-5}$, respectively. This computational behaviour was expected since a value decrease in the scaled residual component imply that the CFD calculation is performed with better accuracy. This fact was also observed in the pressure field computations as shown in Fig. 7, which established the following increasing order of relative error attained at $L=15 \mathrm{~kg} / \mathrm{m}^{2} \mathrm{~s}: 1.0,3.1,10.7$ and $27.1 \%$ for $10^{-2}$, $10^{-3}, 10^{-4}$ and $10^{-5}$, respectively.

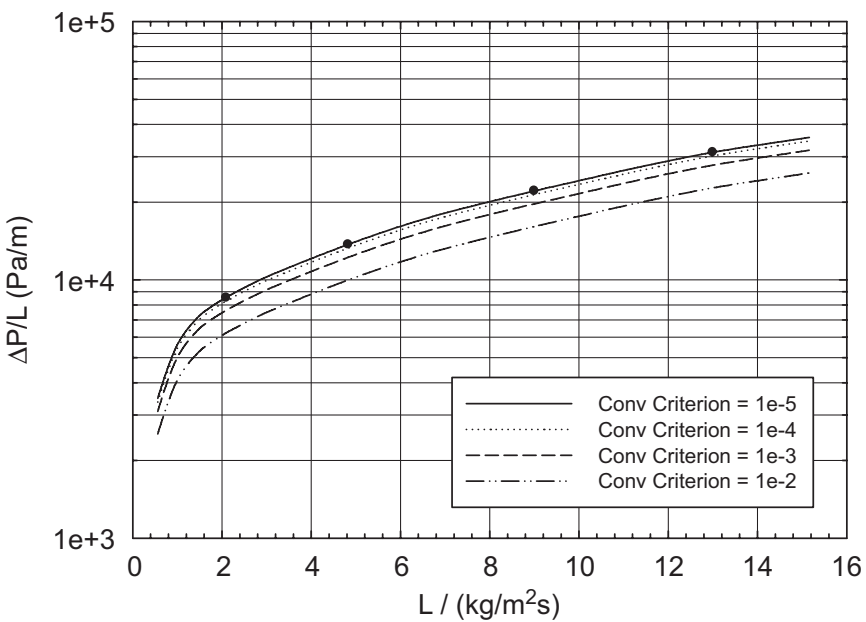

Fig. 7. Effect of convergence criteria on two-phase pressure drop predictions as a function of liquid flow rate (time step $=10^{-5} \mathrm{~s}, 10^{6}$ of tetrahedral cells, $G=0.5 \mathrm{~kg} / \mathrm{m}^{2} \mathrm{~s}$, $P=30$ bar, $d_{p}=2 \mathrm{~mm}$ and experimental data represented by dots from Nemec and Levec, 2005).

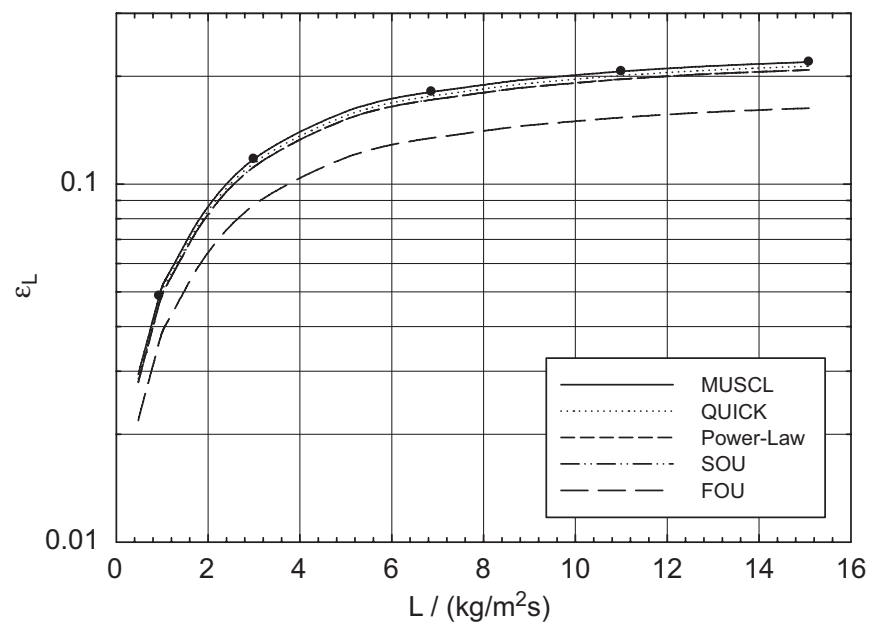

Fig. 8. Effect of discretization scheme of volume fraction equation (MUSCL, QUICK power-law, SOU and FOU) on liquid holdup predictions as a function of liquid flow rate (time step $=10^{-5} \mathrm{~s}, 10^{6}$ of tetrahedral cells, $G=0.1 \mathrm{~kg} / \mathrm{m}^{2} \mathrm{~s}, P=30 \mathrm{bar}, d_{p}=2 \mathrm{~mm}$ and experimental data represented by dots from Nemec and Levec, 2005).

\subsection{Investigation of differencing scheme}

After the base case definition and the achievement of grid size, time step and convergence criteria independent results with respect to both liquid holdup and two-phase pressure drop, five numerical upwind differencing schemes were evaluated for the discretization of momentum equation convective terms including first-order upwind (FOU), second-order upwind (SOU), power-law (PL), quadratic upwind interpolation for convective kinematics (QUICK) and monotonic upwind scheme for conservation laws (MUSCL).

In Fig. 8 it is shown the liquid holdup predictions as a function of liquid flow rate with different discretization schemes at $P=30$ bar and $G=0.1 \mathrm{~kg} / \mathrm{m}^{2} \mathrm{~s}$. Generally, as it can be seen from Fig. 8 second-order computations (SOU) agreed better with liquid holdup experimental data (Nemec and Levec, 2005) for the whole range of simulated liquid flow rate. In fact, the simulation performed at the highest liquid flow rate $\left(L=15 \mathrm{~kg} / \mathrm{m}^{2} \mathrm{~s}\right)$ gave the following decreasing order of relative error: $25.6,4.9,4.9,2.6,1.0 \%$ for FOU, PL, SOU, QUICK and MUSCL, respectively. As one can conclude from these 


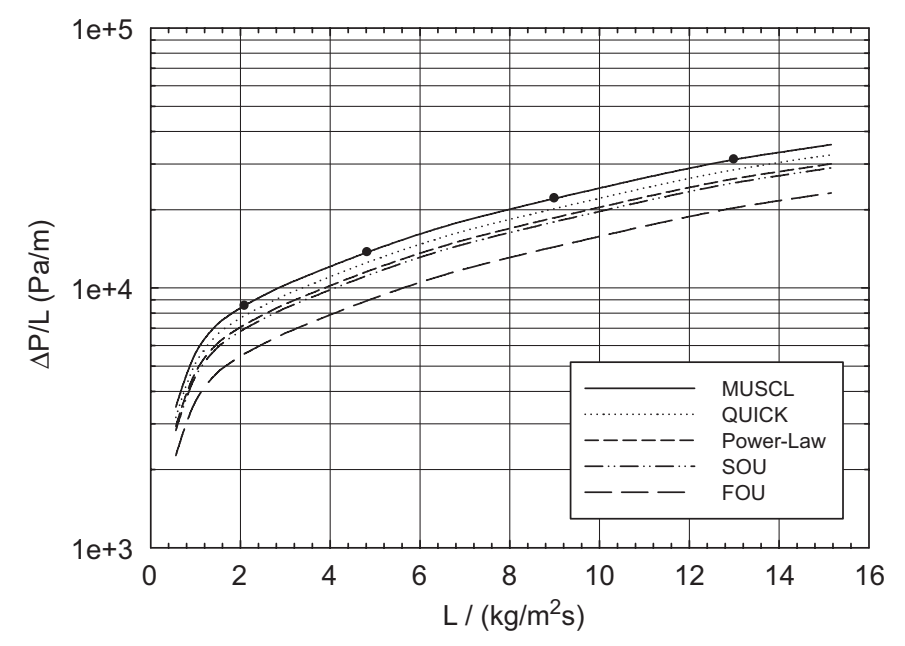

Fig. 9. Effect of discretization scheme of volume fraction equation (MUSCL, QUICK, power-law, SOU and FOU) on two-phase pressure drop predictions as a function of liquid flow rate (time step $=10^{-5} \mathrm{~s}, 10^{6}$ of tetrahedral cells, $G=0.5 \mathrm{~kg} / \mathrm{m}^{2} \mathrm{~s}, P=30 \mathrm{bar}$, $d_{p}=2 \mathrm{~mm}$ and experimental data represented by dots from Nemec and Levec, 2005).

values, as long as the high-order of differencing scheme so do a better concordance was achieved for the liquid holdup simulations. The relative error obtained with PL and SOU was almost the same and its value decreased when the simulation is carried out with QUICK and further MUSCL schemes.

The relative position of differencing schemes in respect to the obtained relative errors is more or less as expected since the third-order quadratic upwind scheme (QUICK) and SOU are generally suited for complex flows than FOU providing a more realistic behaviour in terms of hydrodynamics predictions. Notwithstanding, MUSCL exhibited the minor relative error with less numerical iterations required for convergence probably due to the high-order spatial accuracy and its foundation in total variation diminishing (TVD) scheme (Harten, 1983). TVD schemes are well-known in providing high accuracy numerical solutions to partial differential equations which involves most likely the existence of shocks or discontinuities or even large gradients as characterized by the multiphase flow nature in TBR. It is worth noting that current MUSCL scheme implemented in the CFD solver is a third-order convection scheme conceived from the original MUSCL (Van Leer, 1979) by blending a central-differencing scheme and second-order upwind scheme. Therefore, compared to the second-order upwind scheme, the third-order MUSCL revealed a fair potential to improve spatial accuracy of multiphase flow with the finest mesh $\left(10^{6}\right.$ of tetrahedral cells) by reducing numerical diffusion, most significantly for complex three-dimensional flows in trickle-beds. In Fig. 9, frictional pressure drop predictions are plotted as a function of liquid flow rate with the same investigated differencing schemes for the liquid holdup. Once more, FOU simulations gave the worst agreement with pressure drop experimental data, and both SOU and PL schemes gave approximately the same relative error. As a matter of fact, MUSCL predictions showed again the highest numerical accuracy followed by QUICK simulations. The relative errors obtained at $L=15 \mathrm{~kg} / \mathrm{m}^{2} \mathrm{~s}$ were $34.7,18.5,15.5,8.5$ and $1.0 \%$ for FOU, SOU, PL, QUICK and MUSCL schemes, respectively.

\subsection{Evaluation of RANS turbulence models}

The parametric investigation of mesh size, time step, convergence criteria and momentum equation differencing scheme ascertained CFD independent results with one million tetrahedral cells, $10^{-5} \mathrm{~s}$ for the time step, scaled residuals of $10^{-5}$ with the MUSCL scheme. With

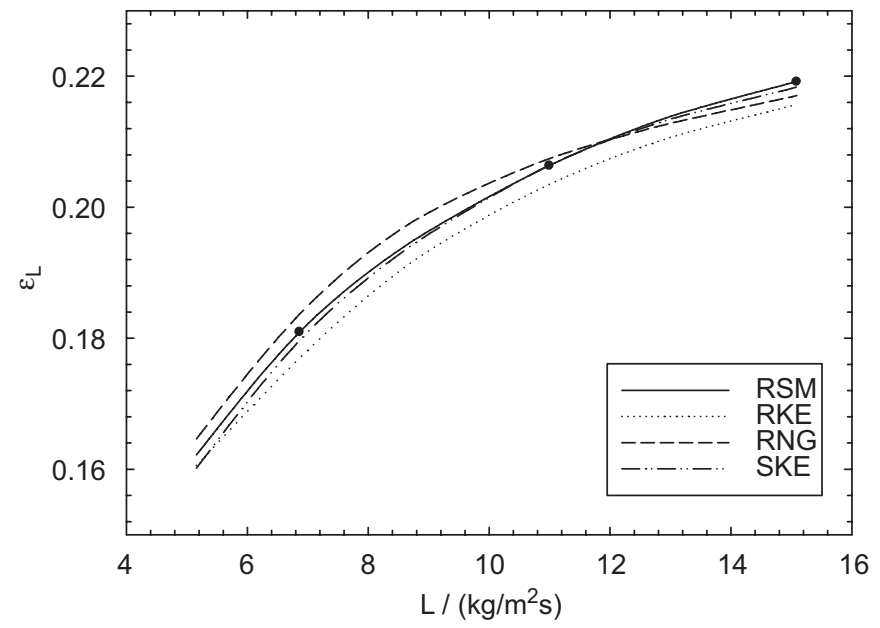

Fig. 10. Influence of RANS turbulence model on liquid holdup predictions as a function of liquid flow rate (MUSCL, time step $=10^{-5} \mathrm{~s}, 10^{6}$ of tetrahedral cells, $G=0.1 \mathrm{~kg} / \mathrm{m}^{2} \mathrm{~s}, P=30 \mathrm{bar}, d_{p}=2 \mathrm{~mm}$ and experimental data represented by dots from Nemec and Levec, 2005).

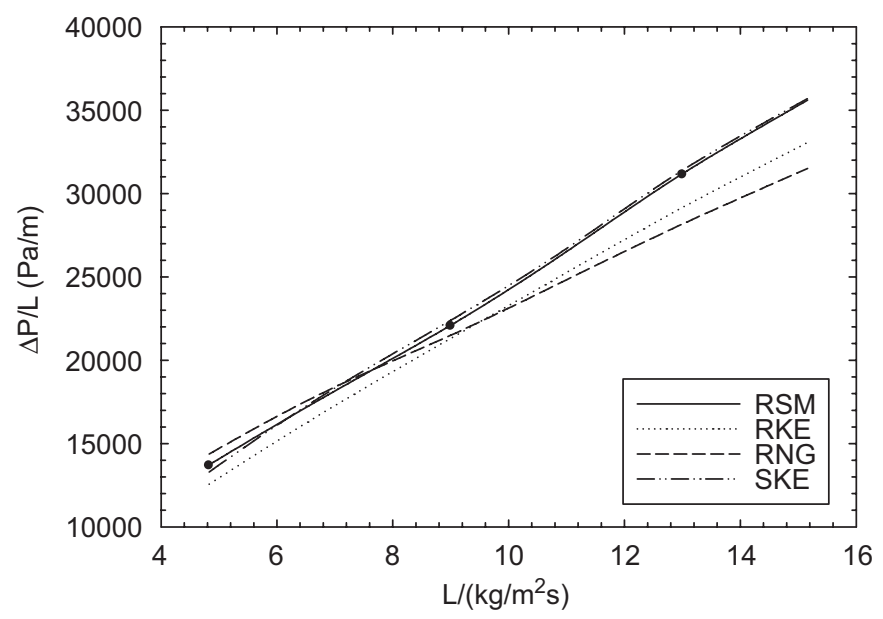

Fig. 11. Influence of RANS turbulence model on two-phase pressure drop predictions as a function of liquid flow rate (MUSCL, time step $=10^{-5} \mathrm{~s}, 10^{6}$ of tetrahedral cells, $G=0.5 \mathrm{~kg} / \mathrm{m}^{2} \mathrm{~s}, P=30 \mathrm{bar}, d_{p}=2 \mathrm{~mm}$ and experimental data represented by dots from Nemec and Levec, 2005).

this case setting, several RANS turbulence models were tested in order to investigate the effect of turbulence model on hydrodynamic parameters. In the context of the $k-\varepsilon$ models (standard (SKE), realizable (RKE) and renormalization group theory (RNG) based models), three multiphase different options were further examined: the mixture turbulence model, the dispersed turbulence model and a per-phase turbulence model. In what concerns theRSM, two options were evaluated including the mixture turbulence and dispersed turbulence models.

In Fig. 10 it is shown the liquid holdup predictions as a function of liquid flow rate at $P=30$ bar and $G=0.1 \mathrm{~kg} / \mathrm{m}^{2} \mathrm{~s}$ for the SKE, RKE, RNG and RSM dispersed turbulence models. As it can be seen, the better concordance was obtained with SKE and RSM models. At the highest simulated liquid flow rate $\left(L=15 \mathrm{~kg} / \mathrm{m}^{2} \mathrm{~s}\right)$, the following increasing order for the relative error was RSM $<$ SKE $<$ RNG $<$ RKE. In spite of the lower relative error attained with RSM simulations, RSM required the highest computing time with around 50,000 of numerical iterations. This fact is probably due to its inherent hypothesis of anisotropic eddy-viscosity as the RSM closes the RANS equations 
a

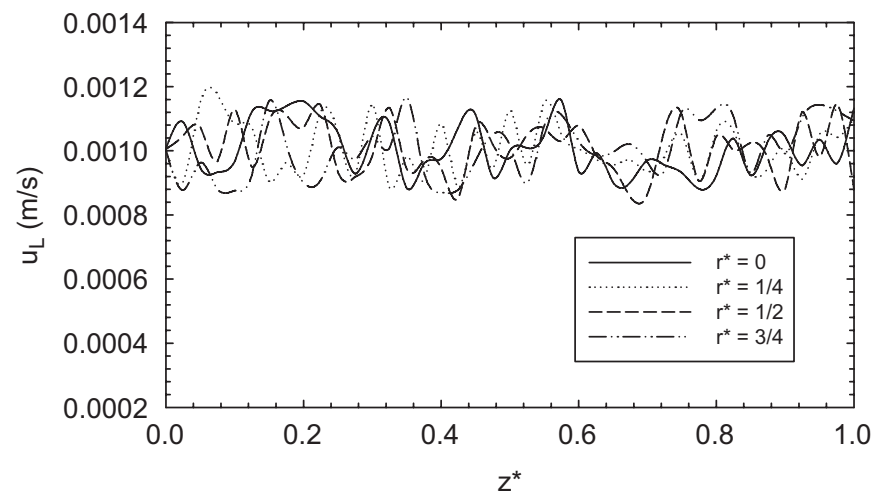

b

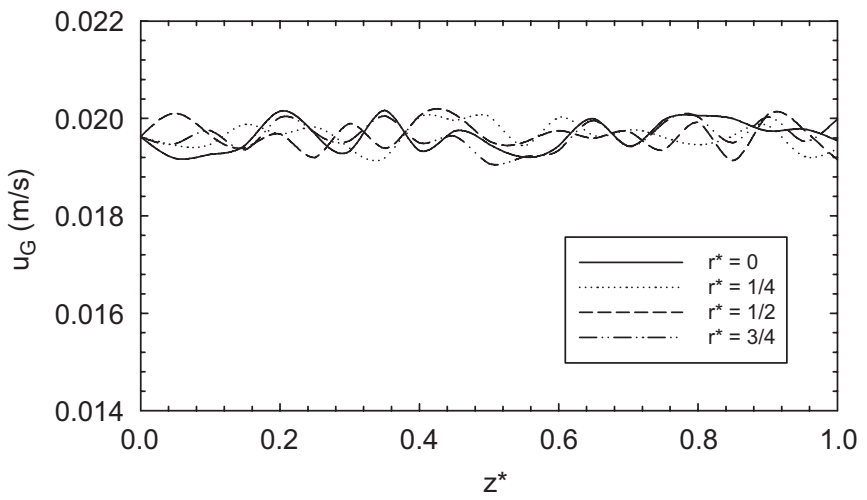

Fig. 12. (a) Axial profile of time-averaged velocity along the packed bed for the liquid and (b) gas phase at $L=1 \mathrm{~kg} / \mathrm{m}^{2} \mathrm{~s}$ and $T=25^{\circ} \mathrm{C}$ (MUSCL, time step $=10^{-5} \mathrm{~s}$, $10^{6}$ of tetrahedral cells, $G=0.7 \mathrm{~kg} / \mathrm{m}^{2} \mathrm{~s}, P=30 \mathrm{bar}, d_{p}=2 \mathrm{~mm}$ ).

by solving transport equations for the Reynolds stresses, together with an equation for the dissipation rate. Moreover, the better numerical accuracy can be also attributed since the RSM accounts for the effects of streamline curvature, swirl, rotation, and rapid changes in strain rate in a more rigorous manner than two-equation turbulence models (as standard $k-\varepsilon$ models). Bearing in mind that multiphase flow in a packed bed poses a great problem to account properly for the boundary layer, it should be pointed out that the reliability of RSM predictions with the finest mesh $\left(10^{6}\right.$ of tetrahedral cells) is still limited by the closure assumptions employed in the exact transport equations for the Reynolds stresses in tricklebeds. Although published works have already indicated that the mesh have to be dense enough in order to capture boundary layer phenomena over the walls (catalyst surface), the Reynolds number dependence of the mesh was found to have no significant effect during all RANS computations, but it should become significant with the increase of Reynolds number (Spalart, 2000).

During the RSM simulations, it was found that pressure-strain and dissipation-rate modelling were responsible for the expensive computations without giving a much different relative error for the liquid holdup (Fig. 10) in comparison with $k-\varepsilon$ dispersed turbulence model. Alternatively, the CFD calculations with RKE and RNG did not show any improvement comparing with SKE. The major differences in the $k-\varepsilon$ models are related with the method of calculating the turbulent viscosity, the turbulent Prandtl numbers of $k$ and $\varepsilon$ and the mathematical formulation of generation and destruction terms in the turbulent dissipation rate. Although RKE accounts for the transport of the mean-square vorticity fluctuation in the turbulent dissipation rate $(\varepsilon)$ equation and RNG theory provides an analytical formula for turbulent Prandtl numbers, after all SKE dispersed turbulence a

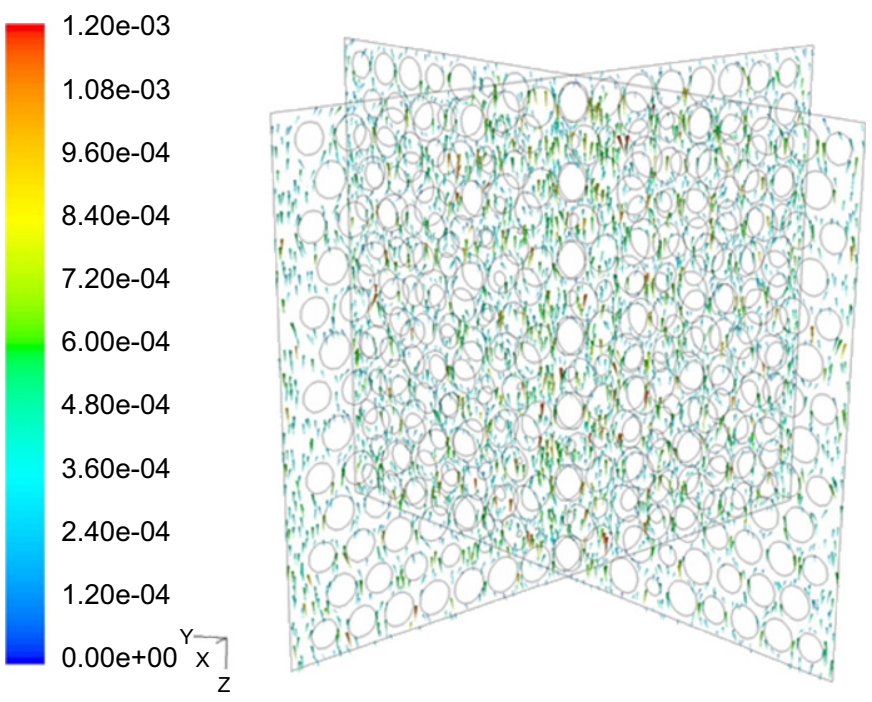

b

$2.0 \mathrm{e}-02$
$1.8 \mathrm{e}-02$
$1.6 \mathrm{e}-02$
$1.4 \mathrm{e}-02$
$1.2 \mathrm{e}-02$
$1.0 \mathrm{e}-02$
$8.0 \mathrm{e}-03$
$6.0 \mathrm{e}-03$
$4.0 \mathrm{e}-03$
$2.0 \mathrm{e}-03 \quad \mathrm{Y} \frac{}{\mathrm{x}}$
$0.0 \mathrm{e}+00$

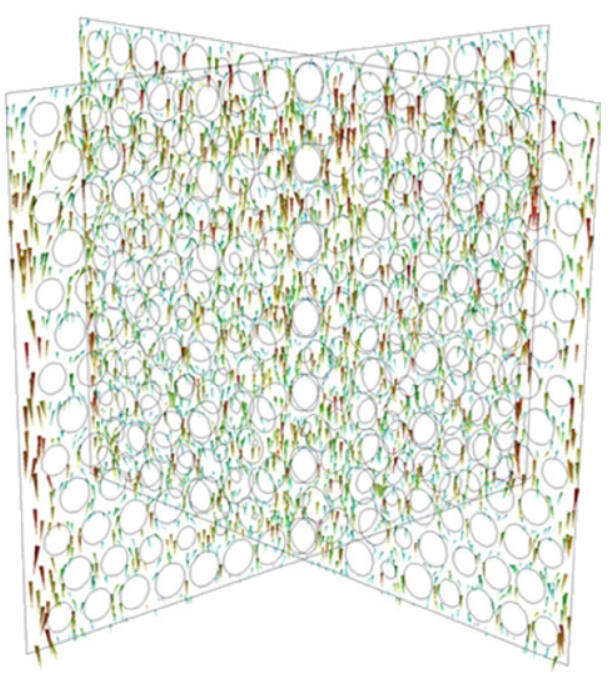

Fig. 13. (a) Velocity vector distribution $(\mathrm{m} / \mathrm{s}$ ) along the packed bed at two orthogonal axial planes for the liquid and (b) gas phase at $L=1 \mathrm{~kg} / \mathrm{m}^{2} \mathrm{~s}$ and $T=25^{\circ} \mathrm{C}$ (MUSCL, time step $=10^{-5} \mathrm{~s}, 10^{6}$ of tetrahedral cells, $G=0.7 \mathrm{~kg} / \mathrm{m}^{2} \mathrm{~s}, P=30 \mathrm{bar}, d_{p}=2 \mathrm{~mm}$ ).

model demonstrated the better compromise between numerical accuracy and computational cost for both liquid holdup and pressure drop predictions. Two-phase pressure drop calculations were plotted in Fig. 11 as a function of liquid flow rate. Once more, RSM agreed better with experimental data followed by SKE, RKE and RNG dispersed turbulence models. The relative errors for the frictional pressure drop were $0.8,1.0,6.3$ and $9.5 \%$ for RSM, SKE, RKE and RNG, respectively.

In order to verify the mesh sensitivity for turbulent simulations, the non-dimensional parameter referred as the cell thickness $\left(y^{+}\right)$ was used to evaluate the mesh size in the wall region. According to Fluent documentation, a value of $30-50$ is recommended but during the trickle-bed simulation this criterion was only verified with the higher flow rates. At the lower flow regimes, too small values were obtained even with the coarsest mesh. If the cell thickness become too large, the wall function will enforce the wall type condition without an appropriate physical meaning. Nevertheless, the good results obtained with both liquid holdup and two-phase pressure predictions indicated that the CFD code is not 
a

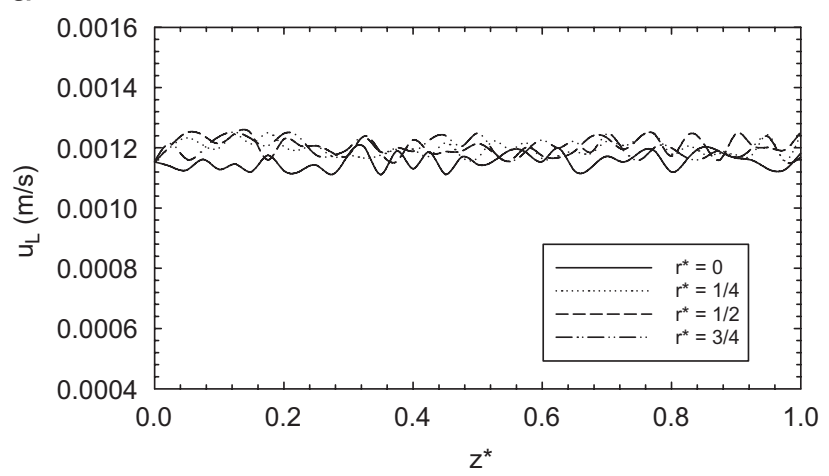

b

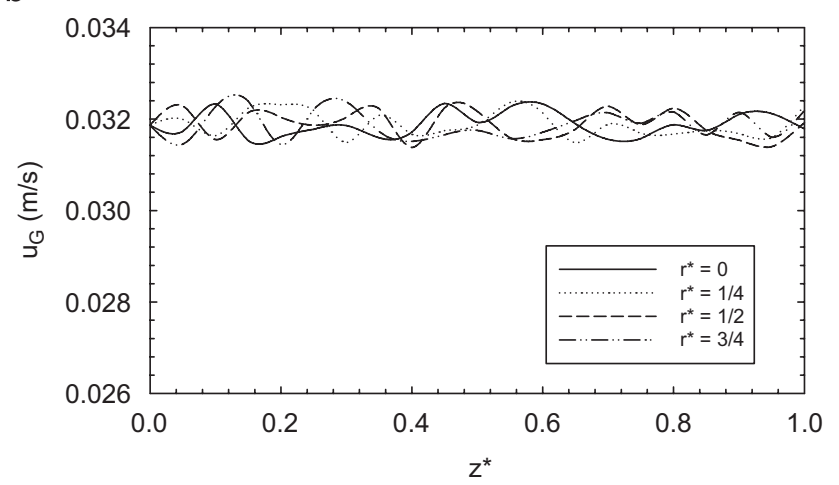

Fig. 14. (a) Axial profile of time-averaged velocity along the packed bed for the liquid and (b) gas phase at $L=1 \mathrm{~kg} / \mathrm{m}^{2} \mathrm{~s}$ and $T=200^{\circ} \mathrm{C}$ (MUSCL, time step $=10^{-5} \mathrm{~s}$, $10^{6}$ of tetrahedral cells, $\left.G=0.7 \mathrm{~kg} / \mathrm{m}^{2} \mathrm{~s}, P=30 \mathrm{bar}, d_{p}=2 \mathrm{~mm}\right)$.

a

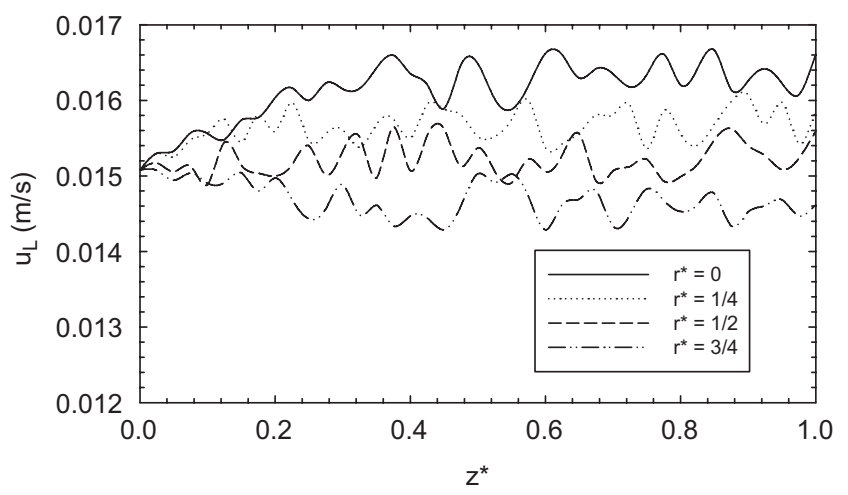

b

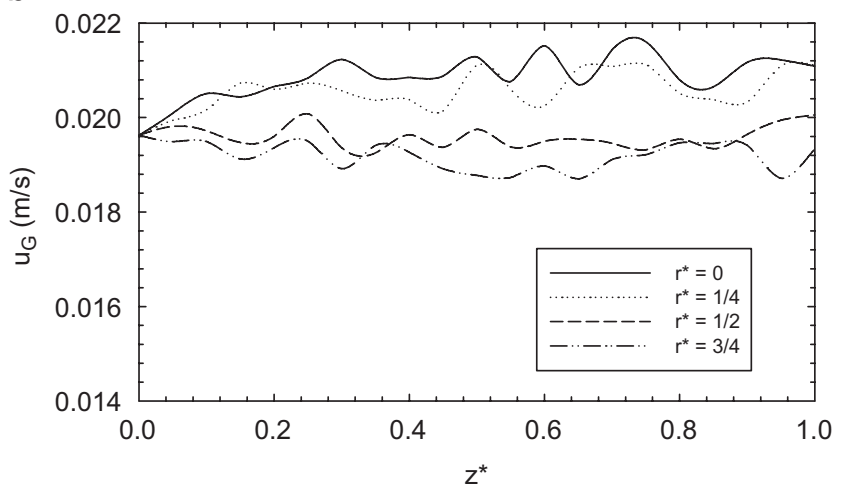

Fig. 15. (a) Axial profile of time-averaged velocity along the packed bed for the liquid and (b) gas phase at $L=15 \mathrm{~kg} / \mathrm{m}^{2} \mathrm{~s}$ and $T=25^{\circ} \mathrm{C}$ (MUSCL, time step $=10^{-5} \mathrm{~s}$, $10^{6}$ of tetrahedral cells, $G=0.7 \mathrm{~kg} / \mathrm{m}^{2} \mathrm{~s}, P=30 \mathrm{bar}, d_{p}=2 \mathrm{~mm}$ ). a

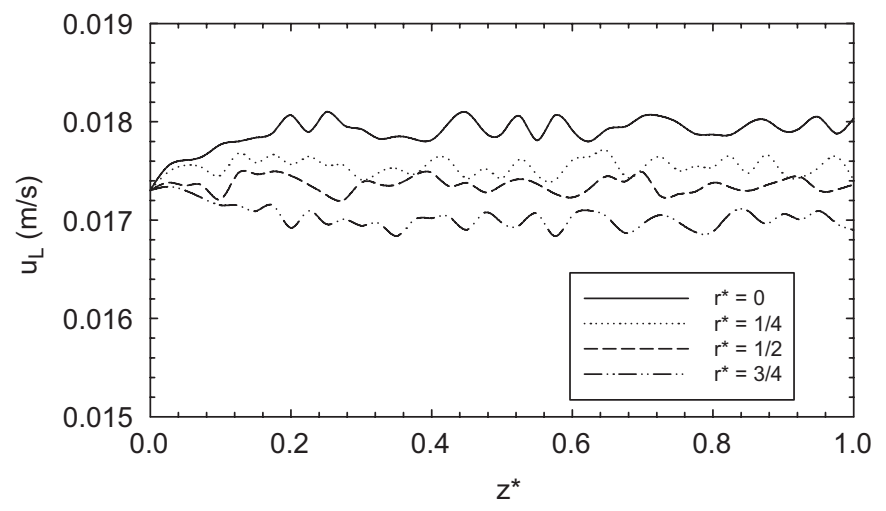

b

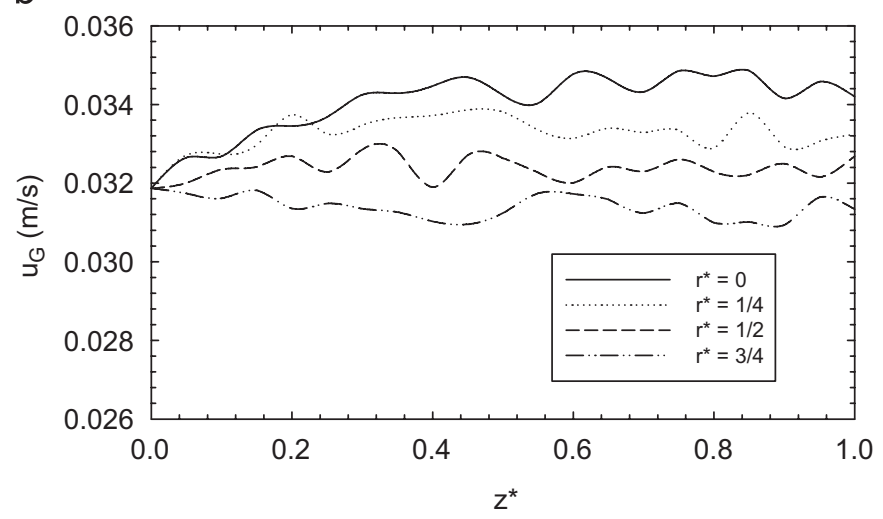

Fig. 16. (a) Axial profile of time-averaged velocity along the packed bed for the liquid and (b) gas phase at $L=15 \mathrm{~kg} / \mathrm{m}^{2} \mathrm{~s}$ and $T=200^{\circ} \mathrm{C}$ (MUSCL, time step $=10^{-5} \mathrm{~s}$, $10^{6}$ of tetrahedral cells, $G=0.7 \mathrm{~kg} / \mathrm{m}^{2} \mathrm{~s}, P=30$ bar, $\left.d_{p}=2 \mathrm{~mm}\right)$.

strongly dependent by the constrain of the $y^{+}$value that was always below 200 .

\subsection{Liquid and gas velocity profiles}

AsTBR are often operated at high temperatures either in petrochemical hydrotreatments or in the catalytic wet oxidations of high strength wastewaters (Bhargava et al., 2006), the effect of temperature on TBR hydrodynamics was evaluated plotting the liquid and gas axial velocities at ambient temperature and at $200^{\circ} \mathrm{C}$. This higher temperature was selected since it is a common value in the organic content decontamination of phenolic wastewaters by means of catalytic wet air oxidation.

In Fig. 12a it is shown the axial profile of time averaged liquid velocity magnitude at $T=25^{\circ} \mathrm{C}, P=30 \mathrm{bar}, G=0.7 \mathrm{~kg} / \mathrm{m}^{2} \mathrm{~s}$ and $L=1 \mathrm{~kg} / \mathrm{m}^{2} \mathrm{~s}$. This time averaging procedure consists in the selection of nominal operating times such as $10,30,60$ and 360 s so that the axial liquid velocity is time-averaged for a single radial coordinate. Four dimensionless radial coordinates were selected: $r^{*}=0, \frac{1}{4}, \frac{1}{2}$ and $\frac{3}{4}$. At the lowest liquid flow rate $\left(L=1 \mathrm{~kg} / \mathrm{m}^{2} \mathrm{~s}\right)$, according to Fig. 12 it was found an oscillatory behaviour for the axial liquid velocity around the mean value of $u_{L}=0.1 \mathrm{~cm} / \mathrm{s}$. The intensity of these oscillations produced by the catalytic bed configuration was quantified with maxima of $15.2 \%$ and minima of $-12.3 \%$ at the TBR centre $\left(r^{*}=0\right)$ and it may be attributed to the existence of different mixing levels at the catalyst scale being almost identical for all radial positions. The axial profile of gas velocity at the same operating conditions is shown in Fig. 12b. With a mean axial velocity value of about $u_{G}=1.96 \mathrm{~cm} / \mathrm{s}$, the maxima and minima values were 
a

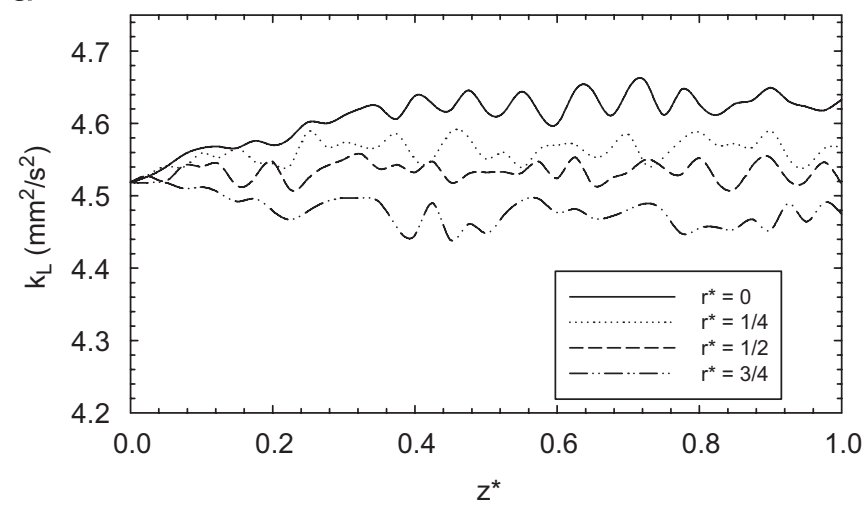

b

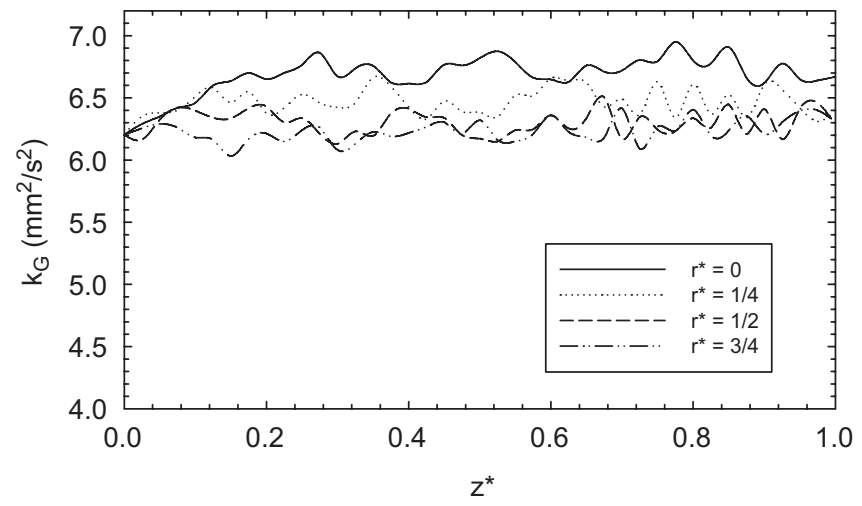

Fig. 17. (a) Time-averaged axial profile of turbulent kinetic energy $\left(\mathrm{mm}^{2} / \mathrm{s}^{2}\right)$ along the packed bed for the liquid and (b) gas phase at $L=15 \mathrm{~kg} / \mathrm{m}^{2} \mathrm{~s}$ and $T=25^{\circ} \mathrm{C}$ (MUSCL, time step $=10^{-5} \mathrm{~s}, 10^{6}$ of tetrahedral cells, $G=0.7 \mathrm{~kg} / \mathrm{m}^{2} \mathrm{~s}, P=30$ bar, $d_{p}=2 \mathrm{~mm}$ ).

2.8 and $-2.3 \%$, respectively. These values were substantially lower than those attained for the axial liquid velocity which indicated an improved homogeneity for the gas velocity spatial distribution. The spatial distribution of axial liquid and gas velocity can be seen in the snapshots of the velocity vector profiles inside the catalytic bed at two orthogonal axial planes as shown in Fig. 13a and b, respectively. According to Fig. $13 \mathrm{a}$, at $T=25^{\circ} \mathrm{C}, P=30 \mathrm{bar}, G=0.7 \mathrm{~kg} / \mathrm{m}^{2} \mathrm{~s}$ and $L=1 \mathrm{~kg} / \mathrm{m}^{2} \mathrm{~s}$ the maxima values were about the same magnitude as observed in Fig. 12a. However, the minima values accomplished in Fig. 13a were lesser than $0.08 \mathrm{~cm} / \mathrm{s}$ for any radial coordinate. The maxima and minima values for the time-averaged axial gas velocity observed in Fig. 12b can also be seen be identified in Fig. 13b. Moreover, the liquid velocity profile attained with the lowest liquid flow rate $\left(L=1 \mathrm{~kg} / \mathrm{m}^{2} \mathrm{~s}\right)$ in Fig. 13a illustrated the existence of flow channelling effects near the catalyst particles. This fact is often regarded as the result of improper liquid distribution at the top of the TBR. For this reason, during all CFD simulations it was mimicked a ideal gas-liquid distributor which prevents or at least limits the extension of liquid maldistribution in trickle-beds.

Fig. 14a shows the axial liquid velocity profile increasing the operating temperature up to $200^{\circ} \mathrm{C}$ maintaining the other operating variables constant $\left(P=30 \mathrm{bar}, G=0.7 \mathrm{~kg} / \mathrm{m}^{2} \mathrm{~s}\right.$ and $\left.L=1 \mathrm{~kg} / \mathrm{m}^{2} \mathrm{~s}\right)$. As one can observe, the intensity the maxima and minima values decreased considerably for both phases whatever the radial coordinated. The maxima and minima values for the time-averaged axial liquid velocity were 4.3 and $-3.7 \%$ whereas for the axial gas velocity that values decreased down to 1.5 and $-1.1 \%$. Therefore, the increase of temperature has a flattening effect on the axial velocity profiles. a

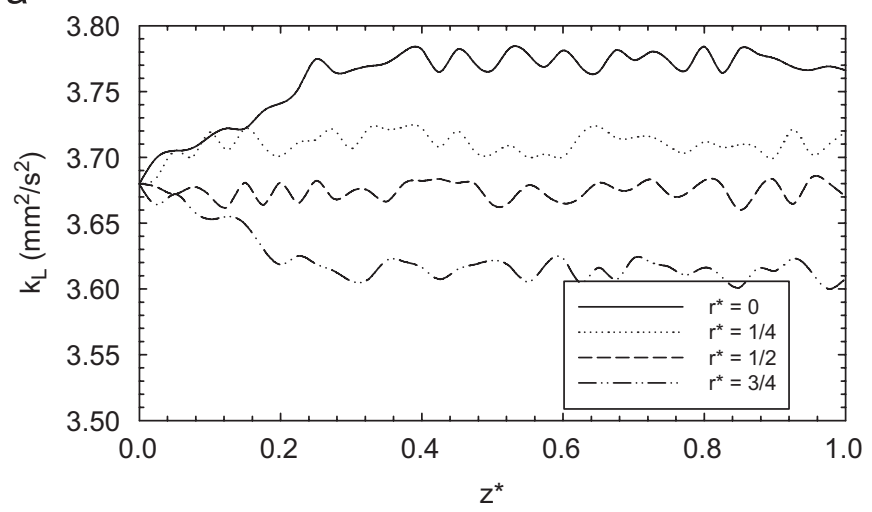

b

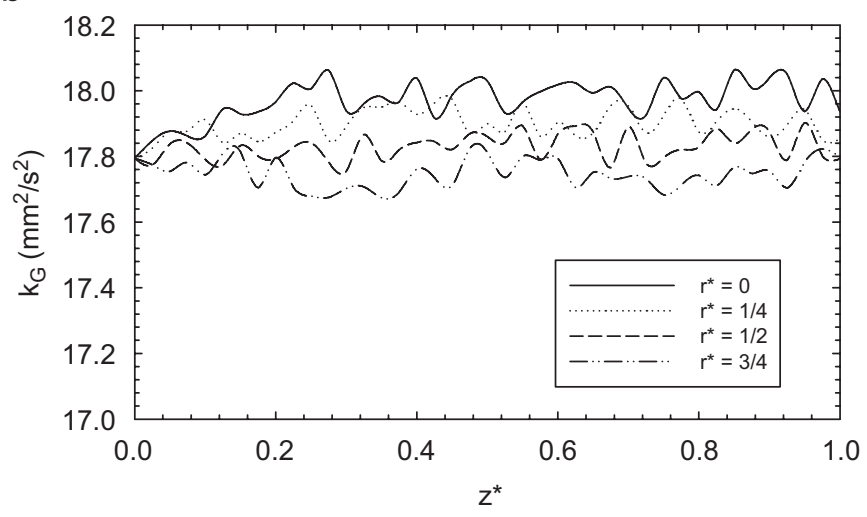

Fig. 18. (a) Time-averaged axial profile of turbulent kinetic energy $\left(\mathrm{mm}^{2} / \mathrm{s}^{2}\right)$ along the packed bed for the liquid and (b) gas phase at $L=15 \mathrm{~kg} / \mathrm{m}^{2} \mathrm{~s}$ and $T=200{ }^{\circ} \mathrm{C}$ (MUSCL, time step $=10^{-5} \mathrm{~s}, 10^{6}$ of tetrahedral cells, $G=0.7 \mathrm{~kg} / \mathrm{m}^{2} \mathrm{~s}, P=30$ bar, $d_{p}=2 \mathrm{~mm}$ ).

As the aforementioned simulations were carried out with the lowest liquid flow rate $\left(L=1 \mathrm{~kg} / \mathrm{m}^{2} \mathrm{~s}\right)$, four additional sets were performed at $L=15 \mathrm{~kg} / \mathrm{m}^{2} \mathrm{~s}, G=0.7 \mathrm{~kg} / \mathrm{m}^{2} \mathrm{~s}, P=30$ bar. Fig. $15 \mathrm{a}$ and $\mathrm{b}$ display the axial liquid and gas velocity profiles at different dimensionless radial coordinates at $T=25^{\circ} \mathrm{C}$. At $r^{*}=0$, the maxima and minima for the liquid velocity were 3.3 and $-6.5 \%$ whereas for the gas velocity those values were 3.5 and $-5.9 \%$, respectively. Comparing these values with those obtained in Fig. 12a and b, the phase velocity profiles were smoothed as long as the liquid flow rate increases from $L=1$ to $15 \mathrm{~kg} / \mathrm{m}^{2} \mathrm{~s}$. This fact can be explained due to the better and improved liquid distribution on the catalyst packing with higher liquid flow rates. In general and in concordance with the hydrodynamic predictions of liquid holdup already discussed, the higher liquid flow rate goes the higher liquid holdup is achieved for the TBR which had a positive effect on the liquid spreading over the particle surface. Furthermore, according to Fig. 15a it can now be observed that different time-averaged axial liquid profiles are obtained for different radial coordinates. Accordingly, the axial liquid velocity profiles begins to diverge as soon as the liquid phase is compelled to flow through the catalytic bed. The higher liquid velocities were attained at the reactor centre and decreased as one moves towards the reactor wall. In order to evaluate also the influence of temperature at the highest simulated liquid flow rate $\left(L=15 \mathrm{~kg} / \mathrm{m}^{2} \mathrm{~s}\right)$, Fig. 16a and $\mathrm{b}$ plot the axial liquid and gas velocity profiles along the catalytic bed at $T=200^{\circ} \mathrm{C}, G=0.7 \mathrm{~kg} / \mathrm{m}^{2} \mathrm{~s}, P=30 \mathrm{bar}$, respectively. As expected, the maxima and minima became slightly lesser to 1.2 , -3.3 and $3.3,-5.9$ for the liquid and gas velocities, respectively. Once again, the divergence behaviour identified early at $T=25^{\circ} \mathrm{C}$ was now smoothened by the temperature increase to $200^{\circ} \mathrm{C}$. 
a

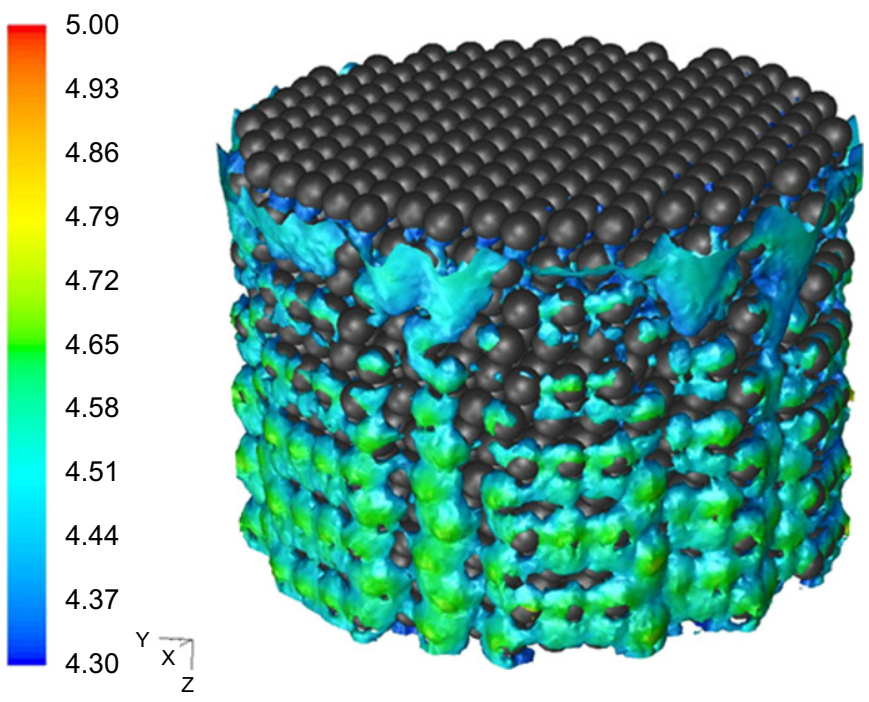

b

\begin{tabular}{l}
6.80 \\
6.69 \\
6.58 \\
6.47 \\
6.36 \\
6.25 \\
6.14 \\
6.03 \\
5.92 \\
5.81 \\
$5.70 \quad \mathrm{Y} \frac{}{\mathrm{X}}$ \\
\hline
\end{tabular}

Fig. 19. (a) CFD snapshot of liquid holdup isosurface $\left(\varepsilon_{L}=0.215\right)$ coloured by turbulent kinetic energy $\left(\mathrm{mm}^{2} / \mathrm{s}^{2}\right)$ for the liquid and (b) gas phase at $L=15 \mathrm{~kg} / \mathrm{m}^{2} \mathrm{~s}$ and $T=25^{\circ} \mathrm{C}$ (MUSCL, time step $=10^{-5} \mathrm{~s}, 10^{6}$ of tetrahedral cells, $G=0.7 \mathrm{~kg} / \mathrm{m}^{2} \mathrm{~s}$, $P=30$ bar, $\left.d_{p}=2 \mathrm{~mm}\right)$.

\subsection{Liquid and gas turbulent kinetic energy profiles}

At $T=25^{\circ} \mathrm{C}, P=30$ bar, $G=0.7 \mathrm{~kg} / \mathrm{m}^{2} \mathrm{~s}$ and $L=15 \mathrm{~kg} / \mathrm{m}^{2} \mathrm{~s}$, the time-averaged axial profile for the liquid turbulent kinetic energy is shown in Fig. 17a for different dimensionless radial coordinates whereas the gas turbulent kinetic energy profile is depicted in Fig. 17b. At the highest simulated liquid flow rate, it was also identified a considerable degree of heterogeneity in the axial turbulent transport properties. As it can be seen, the maxima and minima values were $1.1,-2.0 \%$ and $4.1,-7.1 \%$ for the liquid and gas phases, respectively. Increasing the temperature up $T=200^{\circ} \mathrm{C}$, Fig. $18 \mathrm{a}$ and $b$ show the axial profile of the liquid and gas turbulent kinetic energy profiles. Accordingly, the new maxima and minima values were $0.7,-2.1 \%$ and $0.5,-1.0 \%$, respectively. Once again, whatever the operating temperature the time-averaged turbulent kinetic energy property was deviating from the mean value established at the reactor inlet for either liquid or gas phases. This fact is a direct consequence of the divergence identified early in the time-averaged axial velocity profiles for both phases since the turbulent kinetic energy depends primarily on the phase velocity. At the lower temperature $\left(T=25^{\circ} \mathrm{C}\right)$, it was taken an instantaneous snapshot of a liquid holdup isosurface $(\approx 0.215)$ coloured by the turbulent kinetic energy for the liquid phase as depicted in Fig. 19a whereas in Fig. $19 \mathrm{~b}$ it is shown the gas holdup isosurface $(\approx 0.185)$ coloured by the gas turbulent kinetic energy. As one can observe, the liquid and gas distribution is not uniform at the catalyst scale which identified computationally the so-called flow maldistribution of trickle-beds. This strong axial and radial heterogeneities were observed experimentally by Suekane et al. (2003) by means of a magnetic resonance imaging technique to directly measure the flow in a pore space of a packed bed. Comparing Figs. 17 and 18, in both plots it was detected that the turbulent kinetic energy profiles had amajor magnitude variation for the liquid phase in opposition with the velocity profiles computed at the same operating conditions. Moreover, the increase of the temperature led to a slight decrease in the mean value of the liquid turbulent kinetic energy and an increase of gas turbulent kinetic energy.

\section{Conclusions}

Aiming to understand the effect of turbulence models in multiphase flow, a Euler-Euler model was developed and coupled with different RANS turbulence based modes including standard, realizable and RNG $k-\varepsilon$ models as well as RSM for the hydrodynamics simulation of high-pressure trickle-bed reactor.

First, several computational runs were performed for the parametric investigation of numerical solution parameters. As the accuracy of the simulation is mostly dependent on mesh density, different mesh sizes, time steps, convergence criteria and discretization schemes were compared for the hydrodynamic validation of the multiphase flow model. It was found that CFD predictions with the MUSCL scheme agreed better with the experimental data due to the fact that it is based on TVD algorithm which overcome the numerical dispersion that arose in the multiphase flow simulations.

Second, the optimum values were used for the evaluation purpose of different RANS turbulence models. The standard $k-\varepsilon$ dispersed turbulence was then used to evaluate the influence of flow temperature on axial velocity and turbulent kinetic energy profiles. The increase of temperature was found to be responsible in the smoothness of liquid maldistribution along the packed bed.

\section{Notation}

$\begin{array}{ll}C_{\mu}, C_{1 \varepsilon}, C_{2 \varepsilon}, C_{3 \varepsilon} & k-\varepsilon \text { model parameters: } 0.09,1.44,1.92,1.2 \\ C_{V} & \text { added-mass coefficient: } 0.5 \\ d_{p} & \text { catalyst particle nominal diameter, } \mathrm{m} \\ D_{i} & \text { diffusivity of } i \text { th phase, } \mathrm{m}^{2} / \mathrm{s} \\ \vec{g} & \text { gravitational acceleration, } 9.81 \mathrm{~m} / \mathrm{s}^{2} \\ G & \text { gas mass flux, } \mathrm{kg} / \mathrm{m}^{2} \mathrm{~s} \\ G_{k} & \text { generation rate of turbulent kinetic energy } \\ k & k-\varepsilon \text { model kinetic energy } \\ \tilde{k}_{d c} & \text { covariance of continuous-dispersed phase veloc- } \\ & \text { ity } \\ k_{e f f} & \text { effective thermal conductivity } \\ k_{l p} & \text { covariance of the velocities of the continuous } \\ K_{d c} & \text { phase } q \text { and the dispersed phase } l \\ L & \text { drag coefficient } \\ L_{t, q} & \text { liquid mass flux, kg/m } / \mathrm{m}^{2} \\ p & \text { length scale of the turbulent eddies } \\ \Delta p & \text { pressure, bar } \\ & \text { total pressure drop, Pa }\end{array}$




$\begin{array}{ll}R e_{i} & \text { Reynolds number based on intersticial velocity }[R e / \varepsilon] \\ R_{i j} & \text { Reynolds stresses } \\ S_{i} & \text { source mass for phase } i, \mathrm{ppm} \\ t & \text { time, } \mathrm{s} \\ \vec{u} & \text { superficial vector velocity, } \mathrm{m} / \mathrm{s} \\ \vec{U}_{q} & \text { phase-weighted velocity, } \mathrm{m} / \mathrm{s} \\ \vec{v}_{d r} & \text { drift velocity } \\ \vec{v}_{p q} & \text { relative velocity } \\ x & \text { Cartesian coordinate, } \mathrm{m}\end{array}$

\section{Greek letters}

$\alpha_{i} \quad$ volume fraction of $i$ th phase

$\varepsilon \quad k-\varepsilon$ model dissipation energy

$\kappa \quad$ gas-liquid interface curvature

$\mu_{i} \quad$ viscosity of $i$ th phase, Pa s

$\Pi_{k q}, \Pi_{\varepsilon q} \quad$ influence of the dispersed phases $k$ and $\varepsilon$ on the continuous phase

$\rho_{i} \quad$ density of $i$ th phase, $\mathrm{kg} / \mathrm{m}^{3}$

$\sigma \quad$ surface tension, $\mathrm{Nm}$

$\sigma_{k}, \sigma_{\varepsilon} \quad k-\varepsilon$ model parameters: $1.2,1.0$

$\tau \quad$ residence time, $s$

$\overline{\bar{\tau}}_{i} \quad$ shear stress tensor of $i$ th phase, Pa

$\tau_{F, p q} \quad$ characteristic particle relaxation time connected with inertial effect

$\tau_{t, p q} \quad$ Lagrangian integral time scale calculated along particle trajectories

$\tau_{t, q} \quad$ characteristic time of the energetic turbulent eddies

\section{Subscripts}

$\begin{array}{ll}G & \text { gas phase } \\ i & i \text { th phase } \\ l & \text { dispersed phase } \\ L & \text { liquid phase } \\ q & \text { continuous phase } \\ S & \text { solid phase }\end{array}$

\section{Acknowledgements}

The authors gratefully acknowledged the financial support of REMOVALS-6th Framework Program for Research and Technological Development-FP06 Project no. 018525 and Fundação para a Ciência e Tecnologia, Portugal.

\section{References}

Al-Dahhan, M.H., Larachi, F., Dudukovic, M.P., Laurent, A., 1997. High pressure tricklebed reactors: a review. Industrial and Engineering Chemistry Research 36 (8), 3292-3314.

Anderson, D.H., Sapre, A.V., 1991. Trickle-bed reactors flow simulation. A.I.Ch.E. Journal 37, 377-382.

Atta, A., Roy, Shantanu, Nigam, K.D.P., 2007. Prediction of pressure drop and liquid holdup in trickle bed reactor using relative permeability concept in CFD. Chemical Engineering Science 62 (21), 5870-5879.

Attou, A., Ferschneider, G.A., 1999. Two-fluid model for flow regime transition in gas-liquid trickle-bed reactors. Chemical Engineering Science 54 (21), 5031-5037.

Bhargava, S.K., Tardio, J., Prasad, J., Foger, K., Akolekar, D.B., Grocott, S.C., 2006. Wet oxidation and catalytic wet oxidation. Industrial and Engineering Chemistry Research 45 (4), 1221-1258.

Calis, H.P.A., Nijenhuis, J., Paikert, B.C., Dautzenberg, F.M., van den Bleek, C.M., 2001. CFD modelling and experimental validation of pressure drop and flow profile in a novel structured catalytic reactor packing. Chemical Engineering Science 56, 1713-1720.

Dhole, S.D., Chhabra, R.P., Eswaran, V., 2004. Power law fluid through beds of spheres at intermediate Reynolds numbers: pressure drop in fixed and distended beds. Chemical Engineering Research and Design 82 (A6), 1.

Dybbs, A., Edwards, R.V., 1984. In: Bear, J., Corapcioglu, M. (Eds.), Fundamentals of Transport Phenomena in Porous Media. Martins Nijhoff, Dordrecht.

FLUENT 6.1., 2005. User's Manual to FLUENT 6.1. Fluent Inc. Centrera Resource Park, 10 Cavendish Court, Lebanon, USA
Freund, H., Zeiser, T., Huber, F., Klemm, E., Brenner, G., Durst, F., Emig, G., 2003. Numerical simulations of single phase reacting flows in randomly packed/fixedbed reactors and experimental validation. Chemical Engineering Science 58, 903-910.

GAMBIT 2, 2005. User's Manual to GAMBIT 2. Fluent Inc. Centrera Resource Park, 10 Cavendish Court, Lebanon, USA.

Guardo, A., Coussirat, M., Larrayoz, M.A., Recasens, F., Egusquiza, E., 2005. Influence of the turbulence model in CFD modelling of wall-to-fluid heat transfer in packed beds. Chemical Engineering Science 60, 1733-1742.

Gunjal, P.R., Kashid, M.N., Ranade, V.V., Chaudhari, R.V., 2005a. Hydrodynamics of trickle-bed reactors: experiments and CFD modeling. Industrial and Engineering Chemistry Research 44, 6278-6294.

Gunjal, P.R., Ranade, V.V., Chaudhari, R.V., 2005b. Computational study of a singlephase flow in packed beds of spheres. A.I.Ch.E. Journal 51 (2), 365-378.

Harten, A., 1983. High resolution schemes for hyperbolic conservation laws. Journal of Computational Physics 49, 357-393.

Hill, R.J., Koch, D.L., Ladd, A.J.C., 2001a. Moderate-Reynolds-number flows in ordered and random arrays of spheres. Journal of Fluid Mechanics 448, 243-278.

Hill, R.J., Koch, D.L., Ladd, A.J.C., 2001b. The first effects of fluid inertia on flows in ordered and random arrays of spheres. Journal of Fluid Mechanics 448, 213-241.

Holub, R.A., Dudukovic, M.P., Ramachandran, P.A., 1992. A phenomenological model for pressure-drop, liquid holdup, and flow regime transition in gas-liquid trickle flow. Chemical Engineering Science 47, 2343-2348.

Iliuta, I., Ortiz-Arroya, A., Larachi, F., Grandjean, B.P.A., Wild, G., 1999. Hydrodynamics and mass transfer in trickle-bed reactors: An overview. Chemical Engineering Science 54, 5329-5337.

Iliuta, I., Larachi, F., Al-Dahhan, M.H., 2000. Double-slit model for partially wetted trickle flow hydrodynamics. A.I.Ch.E. Journal 46, 597-609.

Jiang, Y., Khadilkar, M.R., Al-Dahhan, M.H., Dudukovic, M.P., 2002. CFD modeling of multiphase in packed bed reactors: results and applications. A.I.Ch.E. Journal 48, 716-730.

Jolls, K.R., Hanratty, T.J., 1966. Transition to turbulence for flow through a dumped bed of spheres. Chemical Engineering Science 21, 1185-1190.

Latifi, M.A., Midoux, N., Storck, A., Gence, J.N., 1989. The use of micro-electrodes in the study of the flow regimes in a packed bed reactor with single phase liquid flow. Chemical Engineering Science 44, 2501-2508.

Logtenberg, S.A., Nijemeisland, M., Dixon, A.G., 1999. Computational fluid dynamics simulations of fluid flow and heat transfer at the wall particle contact points in a fixed bed reactor. Chemical Engineering Science 54, 2433-2439.

Lopes, R.J.G., Quinta-Ferreira, R.M., 2007. Trickle-bed CFD studies in the catalytic wet oxidation of phenolic acids. Chemical Engineering Science 62 (24), 7045-7052.

Lopes, R.J.G., Quinta-Ferreira, R.M., 2008. Three-dimensional numerical simulation of pressure drop and liquid holdup for high-pressure trickle-bed reactor, Chemical Engineering Journal 145 (1), 112-120.

Magnico, P., 2003. Hydrodynamic and transport properties of packed beds in small tube-to-sphere diameter ratio: pore scale simulation using an Eulerian and a Lagrangian approach. Chemical Engineering Science 58, 5005-5024.

Martin, J.J., McCabe, W.L., Monrad, C.C., 1951. Pressure drop through stacked spheres. Chemical Engineering and Processing 47 (2), 91-94.

Merrikh, A.A., Lage, J.L., 2005. Natural convection in an enclosure with disconnected and conducting solid blocks. International Journal of Heat and Mass Transfer 48, 1361-1372.

Mickley, H.S., Smith, K.A., Korchak, E.I., 1965. Fluid flow in packed beds. Chemical Engineering Science 20, 237-246.

Nemec, D., Levec, J., 2005. Flow through packed bed reactors: 2. Two phase concurrent downflow. Chemical Engineering Science 60 (24), 6958-6970.

Patankar, S.V., 1980. Numerical Heat Transfer and Fluid Flow. Hemisphere, Washington, DC

Rode, S., Midoux, N., Latifi, M.A., Storck, A., Saatdjian, E., 1994. Hydrodynamics of liquid flow in packed beds: an experimental study using electrochemical shear rate sensors. Chemical Engineering Science 49, 889-900.

Romkes, S.J.P., Dautzenberg, F.M., Van Den Bleek, C.M., Calis, H.P.A., 2003. CFD modelling and experimental validation of particle-to-fluid mass and heat transfer in a packed bed at very low channel to particle diameter ratio. Chemical Engineering Journal 96, 3-13.

Sáez, A.E., Carbonell, R.G., 1985. Hydrodynamic parameters for gas liquid cocurrent flow in packed beds. A.I.Ch.E. Journal 31 (1), 52-62.

Saroha, A.K., Nigam, K.D.P., 1996. Trickle bed reactors. Reviews in Chemical Engineering 12, 207-347.

Seguin, D., Montillet, A., Comiti, J., 1998a. Experimental characterisation of flow regimes in various porous media-I: Limit of laminar flow regime. Chemical Engineering Science 53, 3751-3761.

Seguin, D., Montillet, A., Comiti, J., Huet, F., 1998b. Experimental characterization of flow regimes in various porous media-I: Transition to turbulent regime. Chemical Engineering Science 53, 3897-3909.

Sørensen, J.P., Stewart, W.E., 1974. Computation of forced convection in slow flow through ducts and packed beds-III. Heat and mass transfer in a simple cubic array of spheres. Chemical Engineering Science 29, 827-832.

Souadnia, A., Latifi, M.A., 2001. Analysis of two-phase flow distribution in trickle-bed reactors. Chemical Engineering Science 56, 5977-5985.

Spalart, P.R., 2000. Strategies for turbulence modelling and simulations. International Journal of Heat and Fluid Flow 21, 252-263.

Stanek, V., Szekely, J., 1974. Three-dimensional flow of fluids through non-uniform packed beds. A.I.Ch.E. Journal 20, 974-980.

Stevenson, P., 2003. Comment on "Physical insight into the Ergun and Wen \& Yu equations for fluid flow in packed and fluidised beds", by R.K. Niven [Chemical 
Engineering Science, Volume 57, 527-534]. Chemical Engineering Science 58, 5379.

Suekane, T., Yokouchi, Y., Hirai, S., 2003. Inertial flow structures in a simple-packed bed of spheres. A.I.Ch.E. Journal 49, 10-17.

Tobis, J., 2000. Influence of bed geometry in its frictional resistance under turbulent flow conditions. Chemical Engineering Science 55, 5359-5366.

Van der Merwe, D.F., Gauvin, W.H., 1971. Velocity and turbulence measurements of air flow through a packed bed. A.I.Ch.E. Journal 17, 519-528.

Van Leer, B., 1979. Toward the ultimate conservative difference scheme. IV. A second order sequel to Godunov's method. Journal of Computational Physics 32, 101-136.
Vasquez, S.A., Ivanov, V.A., A phase coupled method for solving multiphase problems on unstructured meshes. In: Proceedings of ASME FEDSM'00: ASME 2000 Fluids Engineering Division Summer Meeting, Boston, June 2000.

Wegner, T.H., Karabelas, A.J., Hanratty, T.J., 1971. Visual studies of flow in a regular array of spheres. Chemical Engineering Science 26, 59-63.

Zeiser, T., Steven, M., Freund, H., Lammers, P., Brenner, G., Durst, F., Bernsdorf, J., 2002. Analysis of the flow field and pressure drop in fixed-bed reactors with the help of lattice Boltzmann simulations. Philosophical Transaction of the Royal Society of London A 360 (1792), 507-520. 